\title{
Research Paper \\ Development of Physical-Motor Activities Training Package and Evaluation of its Efficacy on Executive Functions in Children with Attention Deficit / Hyperactivity Disorder
}

\begin{abstract}
Citation: Hashemi Malekshah Sh, Alizadeh H, Rezayi S, Asgari M. Development of a Physical Activity Training Package and Evaluation of its Efficacy on Executive Functions in Children with Attention Deficit / Hyperactivity Disorder. J of Psychological Science. 2021; 20(104): 1279-1294.
\end{abstract}

Shahnaz Hashemi Malekshah', Hamid Alizadeh ${ }^{2}$, Saeed Rezayi ${ }^{3}$, Mohammad Asgari ${ }^{4}$

1. Ph.D Student of Psychology and Exceptional Children Education, Allameh Tabataba'i University, Tehran, Iran.

2. Professor, Department of Psychology and Exceptional Children Education, Allameh Tabataba'i University, Tehran, Iran. 3. Assistant Professor, Department of Psychology and Exceptional Children Education, Allameh Tabataba'i University, Tehran, Iran. 4. Associate Professor, Department of Assessment and Measurement, Allameh Tabataba'i University, Tehran, Iran.

URL: https://psychologicalscience.ir/article-1-1334-fa.html
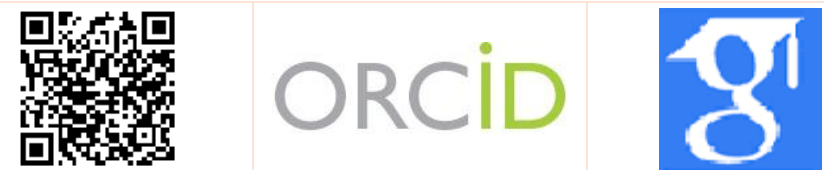

10.52547/JPS.20.104.1279
A R T I C L E I N F O

Keywords:
Physical - Motor
Activities,
Executive Functions,
Children with Attention
Deficit / Hyperactivity
Disorder

Received: 15 Jul 2021

Accepted: 05 Aug 2021

Available: 23 Oct 2021

\section{A B S T R A C T}

Background: Various studies revealed the effectiveness of physical activity training programs on executive functions in the children with attention deficit-hyperactivity disorder (ADHD). Hence, examining the impact of the interventional strategies of physical and motor activities on executive functions in the children with ADHD has had some limitations.

Aims: This study aimed to develop a training package of Physical-Motor Activities and evaluate its impact on executive functions of children with ADHD.

Methods: The present study was applied in terms of purpose and the method of combined type (qualitative and quantitative) as the qualitative part of treatment plan and the quantitative part of quasi-experimental method with unbalanced control group design and follow-up session. Statistical population in the qualitative section is based on the theories of Barkley (2015) and includes experts in the field of child motor skills and research published in prestigious journals from 1390 to 1399 for Persian articles and from 2000 to 2020 for the English articles in the field of motor interventions for children with ADHD. The quantitative part included all boys with ADHD aged 7-12 years in the primary schools of the $16^{\text {th }}$ district of Tehran. For sampling among the schools in District 16 , four schools were selected as available, and 30 children with ADHD were identified in those schools and then randomly assigned to two experimental and control groups (each group including 15 children). The instruments used in this study were Diagnostic Questionnaires of ADHD (APA 2013) and BRIEF for the executive functions (Gioia et al., 2000). The children in the experimental group participated in the training program in 24 sessions of 60 minutes. Data were analyzed using a mixed analysis of variance.

Results: In the qualitative part, research results showed that the training package had sufficient content validity in the opinion of experts. In the quantitative part, the results manifested that by controlling the pre-test, the training package of physical-motor activities caused a significant improvement in the components of attention, inhibition, and working memory $(p<0.001)$ in the experimental group compared to control group. However, there was no change in the planning and organizing components of the experimental group compared to control group ( $\mathrm{p}>0.001$ ).

Conclusion: Overall the result of the present study showed that physical-motor activities training program has positive effects on executive functions of children with ADHD.

* Corresponding Author: Shahnaz Hashemi Malekshah, Ph.D Student of Psychology and Exceptional Children Education, Allameh Tabataba'i University, Tehran, Iran.

E-mail: hashemimalekshah92@gmail.com

Tel: (+98) 2166849982

2476-5740/ (C) 2021 The Authors. This is an open access article under the CC BY-NC-ND license

(https://creativecommons.org/licenses/by-nc/4.0/). 


\section{Monthly Journal of Psychological Science}

\section{Extended Abstract}

\section{Introduction}

Children with Attention Deficit / Hyperactivity Disorder have major deficiencies in most components of executive functions including impaired consistent attention, lack of inhibition, impaired working memory, and poor planning and organization (Barkley, 2015). Drug therapies can improve the executive function of these children but do not cause any lasting structural change in the neurons (Marcus et al., 2005). Based on Barkley's Behavioral Inhibition Model, such a treatment is useful for these children, which occurs in a natural environment and at a point of performance. For this purpose, special tools and programs can be used at home and school and sport situations (Barkley, 2004). Individuals who engage in physical and motor activities can activate areas of the frontal and parietal parts of brain which are involved in executive functions (Neudecker et al., 2015).

Various studies were conducted on the effects of physical activity. Piepmeier et al. (2015), in their research, showed that physical activity has an effect on the inhibition component of these children, but has no effect on attention, organization, and planning. Schmidt et al. (2013) in their study, stated that physical activity has a significant effect on the inhibition of these children. Verret et al. (2012) did not report a significant difference in inhibition in the behavior of these children after performing a 30 session physical activity program, but the results on the performance of attention were significant. Ziereis \& Jansen (2015), in their research, showed that physical activity affects the working memory of these children. Some researchers believe that physical activity has greater benefits over executive functions due to the complexity of tasks which involve cognitive and motor stimuli, as opposed to activities which are based solely on the motor or cognitive (Verret et al., 2012).

Therefore, due to the contradictions in the findings, as well as the limited evidence that there is a positive effect of physical activity on executive functions in these children, the researcher in the present study seeks to answer the question of whether the
Vol. 20, No. 104, Autumn(November) 2021

development of a physical activity training program can be effective on the executive functions of attention, inhibition, working memory, planning, and organization in children with ADHD or not.

\section{Method}

The present study was applied in terms of purpose and the method of combined type (qualitative and quantitative) as the qualitative part of treatment plan and the quantitative part of quasi-experimental method with unbalanced control group design and follow-up session. Statistical population in the qualitative section is based on the theories of Barkley (2015) and includes experts in the field of child motor skills and research published in prestigious journals from 1390 to 1399 for Persian articles and from 2000 to 2020 for the English articles in the field of motor interventions for children with ADHD and the quantitative section included all boys with ADHD aged 7-12 years in the primary school of 16th district of Tehran. In the qualitative part, sampling was based on keywords and related texts. In the quantitative section, for sampling among the schools in District 16 , four schools were selected as available, and 30 children with ADHD were identified in those schools and then randomly assigned to two experimental and control groups (each group including 15 children). Intrance criteria for children includes normal intelligence, attention deficit / hyperactivity disorder, age 7-12 years, male gender, voluntary and parental consent of the child, no neuromuscular and heart problems, and effective vision and hearing problems. Exclusion criteria for children included the association of this disorder with developmental coordination disorder, drug use due to interference in executive functions, and lack of cooperation of samples in regular attendance at training sessions. The instruments used in the qualitative section were extracted texts and in the quantitative section were Diagnostic Questionnaires of ADHD (APA 2013) with a reliability of 0.85 and BRIEF for executive functions (Gioia et al., 2000) with a reliability of 0.93 . The children in the experimental group participated in the training program in 24 sessions of 60 minutes (12 sessions of basic training and 12 sessions of repetition and practice), but the control group was not given training. To analyze the data in the qualitative part, 


\section{Monthly Journal of Psychological Science}

the inductive content analysis method was used, and in the quantitative part, descriptive statistics (mean and standard deviation) and inferential statistics (mixed analysis of variance) were used.

\section{Results}

In the qualitative section, a review of texts related to motor physical activity using inductive content analysis method, 6 main categories of basic motor
Vol. 20, No. 104, Autumn(November) 2021

exercises and displacement, balance, deep sense, coordination, speed and agility, and aerobic were shown.

In the quantitative section of data analysis, mixed analysis of variance was used to evaluate the effectiveness of physical activity training package on executive functions of attention, inhibition, working memory, planning, and organization of children with ADHD.

\begin{tabular}{|c|c|c|c|c|c|c|c|c|}
\hline Variable & \multicolumn{2}{|c|}{ Source of change } & SS & DF & SM & $\mathrm{F}$ & Sig & Effect size \\
\hline \multirow{3}{*}{ Inhibition } & \multirow{2}{*}{ Within group } & Stage & 268.29 & 2 & 134.14 & 81.574 & 0.001 & 0.744 \\
\hline & & Stage * Group & 274.29 & 2 & 137.14 & 83.399 & 0.001 & 0.749 \\
\hline & Between group & Group & 440.01 & 1 & 440.01 & 26.703 & 0.001 & 0.488 \\
\hline \multirow{3}{*}{ Attention } & \multirow{2}{*}{ Within group } & Stage & 84.27 & 2 & 42.13 & 31.027 & 0.001 & 0.526 \\
\hline & & Stage * Group & 103.02 & 2 & 51.51 & 37.933 & 0.001 & 0.575 \\
\hline & Between group & Group & 111.11 & 1 & 111.11 & 15.254 & 0.001 & 0.353 \\
\hline \multirow{3}{*}{ Working Memory } & \multirow{2}{*}{ Within group } & Stage & 13.36 & 2 & 6.68 & 6.423 & 0.003 & 0.187 \\
\hline & & Stage * Group & 29.76 & 2 & 14.88 & 14.310 & 0.001 & 0.338 \\
\hline & Between group & Group & 59.21 & 1 & 59.21 & 4.257 & 0.012 & 0.206 \\
\hline \multirow{3}{*}{ Organization } & \multirow{2}{*}{ Within group } & Stage & 2.47 & 2 & 1.23 & 2.417 & 0.098 & 0.709 \\
\hline & & Stage * Group & 0.29 & 2 & 0.14 & 0.283 & 0.755 & 0.010 \\
\hline & Between group & Group & 3.21 & 1 & 3.21 & 0.255 & 0.617 & 0.009 \\
\hline \multirow{3}{*}{ Planning } & \multirow{2}{*}{ Within group } & Stage & 10.69 & 2 & 5.34 & 6.648 & 0.003 & 0.192 \\
\hline & & Stage * Group & 0.29 & 2 & 0.14 & 0.180 & 0.836 & 0.006 \\
\hline & Between group & Group & 2.84 & 1 & 2.84 & 0.142 & 0.709 & 0.005 \\
\hline
\end{tabular}

The results of Table 1 show a significant effect for the group factor, stage and stage interaction with the group in the inhibition component $(\mathrm{Eta} 2=0.749, \mathrm{P}$ $<0.001, \mathrm{~F}=83.3)$, attention $(=0.575$ There is Eta2, $\mathrm{P}$ $<0.001, \mathrm{~F}=37.9)$ and working memory $(\mathrm{P}=0.008$, Eta2, $\mathrm{P}=0.001, \mathrm{~F}=10 / 14)$. But, in the components of organization and planning, the effect of between group is not significant.

Furthermore, the results of Ben Foroni post hoc test showed that in the components of inhibition, attention and working memory, the difference between pre-test and post-test, and comparing pre-test and follow-up pairs in the experimental group was significantly different $(p=0<001)$ and the effectiveness of training was lasting until follow-up. But, the scores of the components of planning and organizing the experimental group in the stages of pre-test, post-test and follow-up were not significantly different $(\mathrm{P}=$ $0>001)$. In the control group, none of the differences among the scores of components in the measurement stages were not significant.

\section{Conclusion}

In the qualitative part, the research results showed that the training package had sufficient content validity in the opinion of experts. One of the salient advantages of physical activity over other therapies is using movement-based exercises which due to having a visible and measurable output, as well as using physical activity which is itself a symptom of attention deficit / hyperactivity disorder can be eliminated Cognitive limitations in these individuals and provide significant results.

In the qualitative part ,the research results showed that the educational program improved the executive functions in children with ADHD in the components of attention, inhibition and working memory, but had no effect on the components of planning and organization. This finding is in line with the research of Schmidt et al. (2013) in the component of attention, Chang et al. (2014) in inhibition component, Ziereis $\&$ Jansen (2015) in the working memory component, and research results of Schmidt et al. (2013), Piepmeier et al. (2015) in the components of planning and organizing. Regular physical activity plays a 
crucial role in regulating the attention of these children by increasing the level of neurotransmitters in the brain (Gapin et al., 2011). Physical activity also increases dopamine levels and improves the function of basal ganglia in the brain, thereby improving response inhibition (Varma \& Raju, 2012) .Besides, activation of beta-adrenergic receptors by increasing the norepinephrine transporter due to physical activity increases the expression of brain-derived neurodevelopmental factor (BDNF) gene and thus enhances memory (Hopkins et al., 2011). In explaining the lack of effect of training program on the components of planning and organizing, there is some evidence that not all executive functions are equally sensitive to the impact of physical activity (Gapin \& Etnier, 2014). Lack of effect of physical activity on some components of executive functions may be due to different components of executive functions which have different growth pathways. (Best, 2010). Overall the result of the present study showed that physical-motor activities training program has positive effects on executive functions of children with ADHD.

\section{Ethical Considerations}

Compliance with ethical guidelines: The authors extracted this article from the $\mathrm{PhD}$ dissertation of the first author, which approved under No 407 date, 23.11.2020 in the Faculty of Psychology, Allameh Tabataba'i University, Tehran. Ethical approval was obtained from the Research Ethics Committee of the University of Allameh Tabataba'i University (IR.ATU.REC.1399.050). Ethical considerations like gaining the informed consent of the participants and the confidentiality of responses were considered in this research.

Funding: This study was conducted as a $\mathrm{PhD}$ thesis with no financial support.

Authors' contribution: The first author was the senior author, the second were the supervisors and the third and forth was the advisors.

Conflict of interest: the authors declare no conflict of interest for this study.

Acknowledgments: I would like to appreciate the supervisor, the advisors, the parents and participants in the study. 


\section{تدوين بسته آموزشى فعاليتهاى بدنى - حر كتى و بروسى اثربخشى آن بر كاركردهاى اجرايى در كودكان با اختلال كمبود توجه / فزون كنشى}

\section{شهناز هاشمىملكشاه"'، حميد عليز اده '، سعيد رضايى"، محمد عسكرى}

1. دانشجوى دكترى روانشناسى و آموزش كود كان استثنايى، دانشكاه علامه طباطبائى، تهران، ايران.

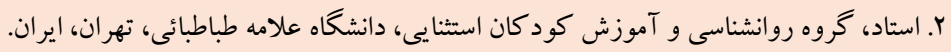

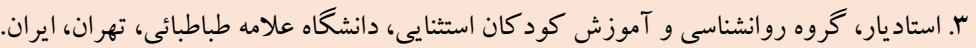

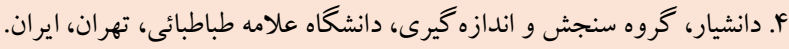

جكيده

زمينه: يزوهشهاى مختلف حاكى از تأثير برنامه آموزشى فعاليتهاى بدنى بر كاركردهاى اجرايى كود كان با اختلال كمبود توجه / فزون

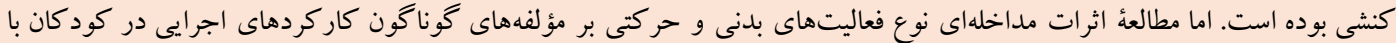
اختلال كمبود توجه / فزون كنشى محدود بوده است.

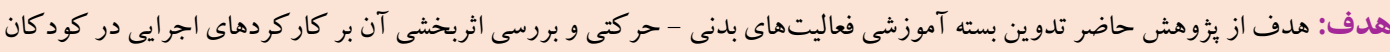
با اختلال كمبود توجه / فزون كنشى بود.

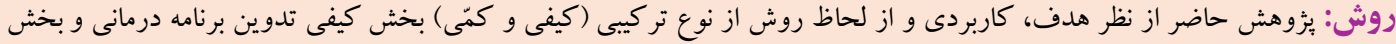

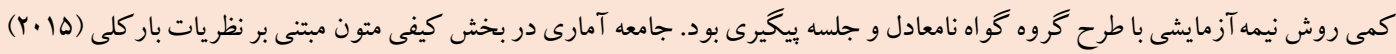

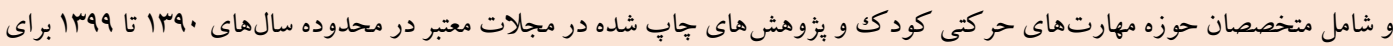

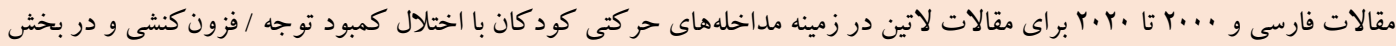

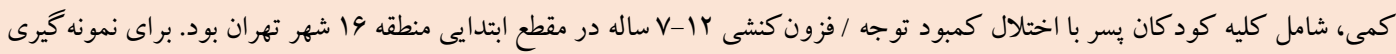

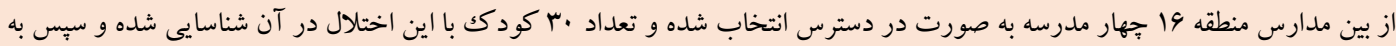

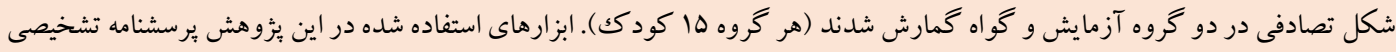

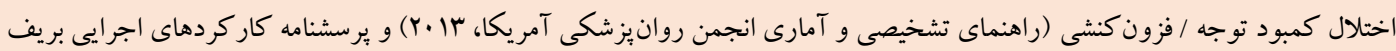

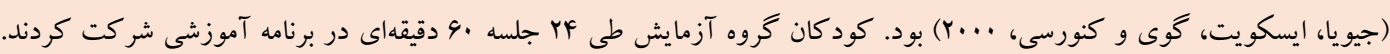

دادهها با استفاده از آزمون تحليل واريانس آميخته تجزيه و تحليل شد.

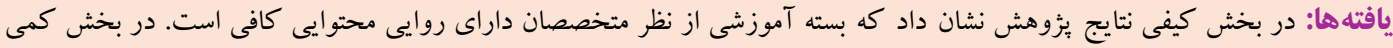

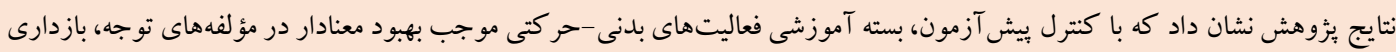

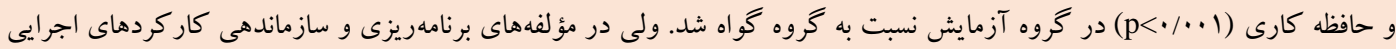

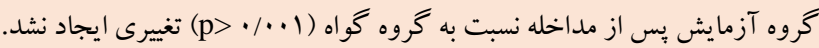

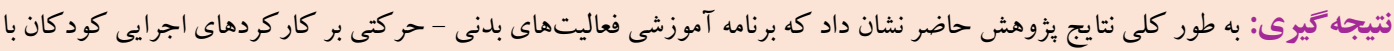
اختلال كمبود توجه / فزون كنشى اثرات مثبتى به همراه دارد.
مشخصات مقاله

كليدوازهها:

فعاليتهاى بدنى - حر كتى،

كار كردهاى اجرايى،

كود كان با اختلال كمبود توجه إنكائ

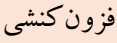

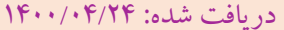
|F

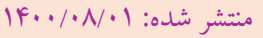

* نويسنده مسئول: شهناز هاشمىملكشاه، دانشجوى دكترى روانشناسى و آموزش كود كان استثنيى، دانشكاه علامه طباطبائى، تهر ان، ايران. hashemimalekshah92@gmail.com راياناهـ 
rا.r). برنامهريزى ارتباط نزديكى با حافظه كارى داشته و مىتواند بر

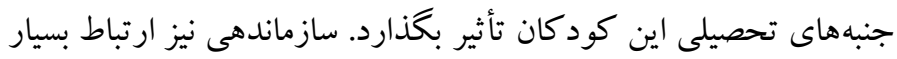

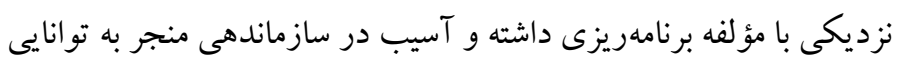

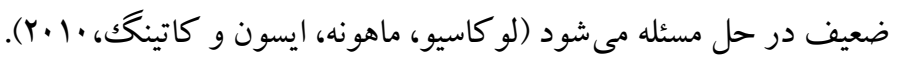
در دو دهه اخير يُزوهشهاى بسيارى نشان دادهاند كه نقص در مؤلفهاى

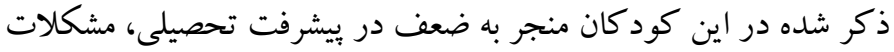
رفتارى، نقص در عملكرد اجتماعى و كنترل هيجان مى شود (بست، • ·. (Y).

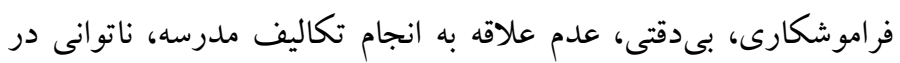

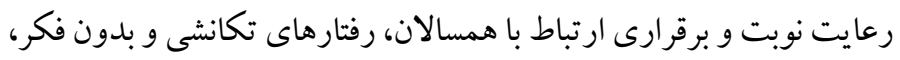

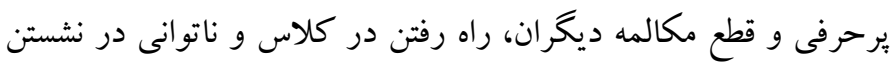
روى صندلى از جمله يِامدهاى نقص در كاركردهاى اجرائى در اين

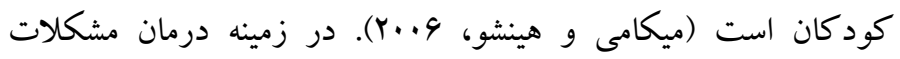
كاركردهاى اجرايى، درمانهاى دارويى مىتوانند كاركردهاى اجرايى

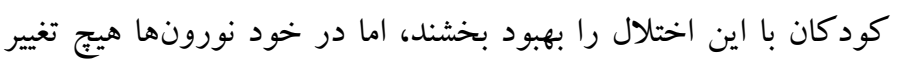

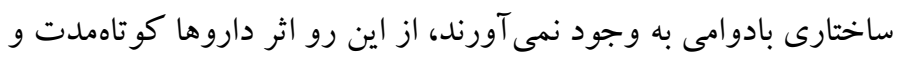

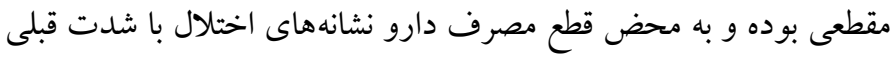

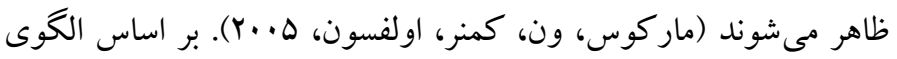

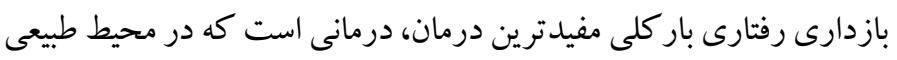
و در نقطهى عملكردى ورخ مىدهد. نقطهى عملكردى نكته كليدى در

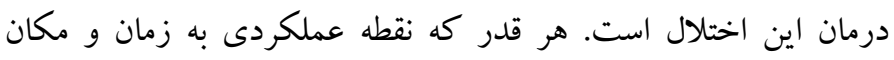
نزديككتر باشد درمان اختلال كارآمدتر خواهد بود. براى درمان در موقعيت هاى طبيعى مى توان از برنامه هاى تغيير رفتار و هدف قرار دادن رفتار مطلوب و حفظ آن در طول زمان استفاده كرد. براى اين منظور مى توان ان از ابزارها و برنامههاى ويثه در خانه و مدرسه و موقعيتهاى ورزشى استفاده

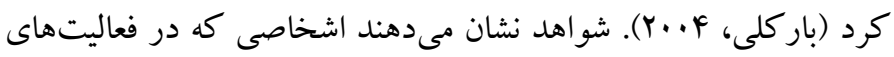

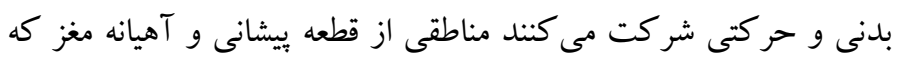
مربوط به كار كردهاى اجر ايى است در آنها فعال مى شود (نئودكر و ريمرز

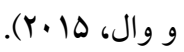

يثزوهش هاى مختلفى در زمينه تأثير فعاليتهاى بلدنى بر كار كردهاى اجرايى

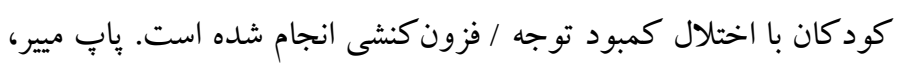

4. Cerebellum

5. Singulate Frontal

${ }^{6}$. Point of Performance
مقام dold

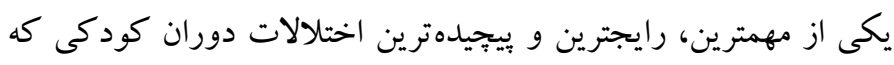

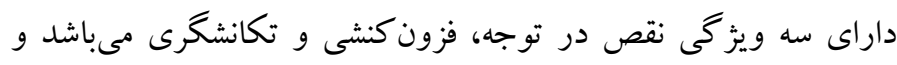
اغلب تا دوران بزر كسالى نيز ادامه بيدا مى كند، اختلال كمبود توجه ونه /

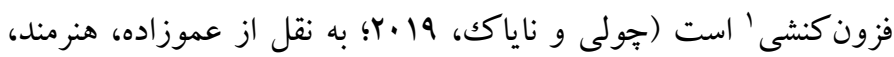

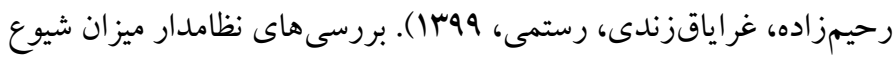

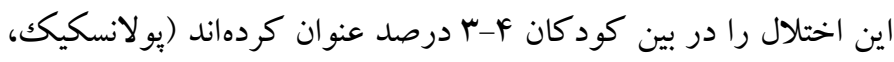

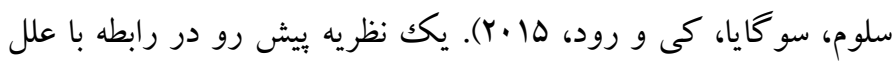

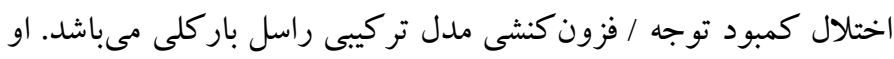

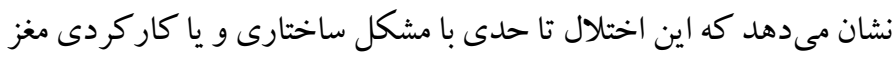

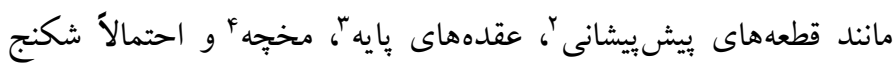

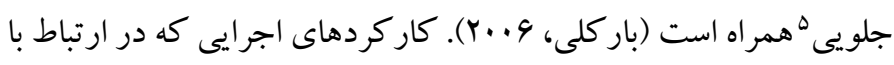

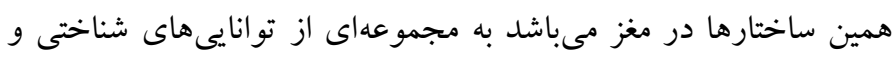

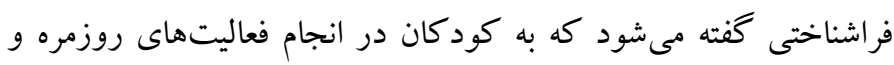

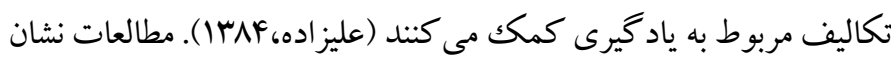

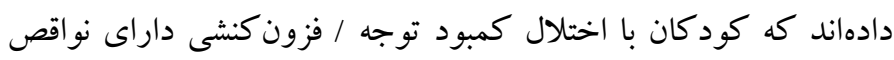

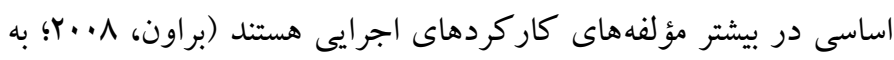

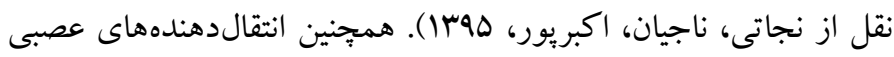

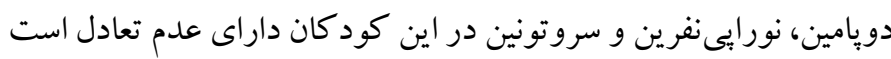
(وريت، كاى، برسيام، كاردينر و بليوياى، با. (Y).

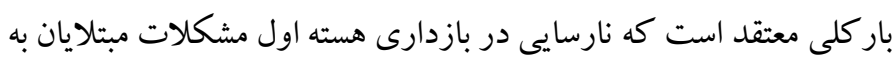

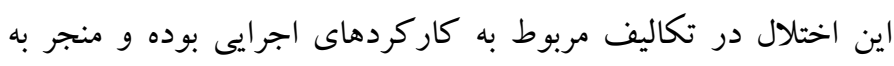

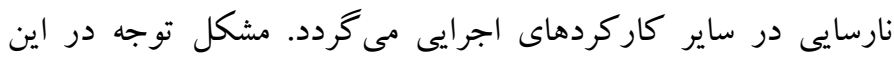

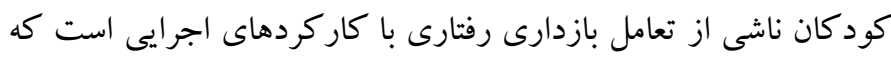

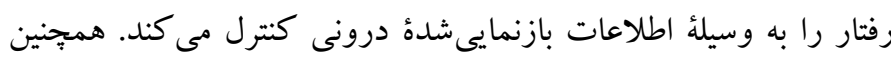
عدم بازدارى باسخ از طريق ايجاد نقص در حافظه كارى سبب ايجاد رفتارهاى فزون كنشى در اين كود كان مىشود (بار كلى، ها ب. Y).

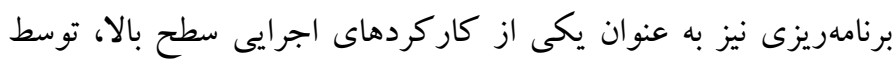

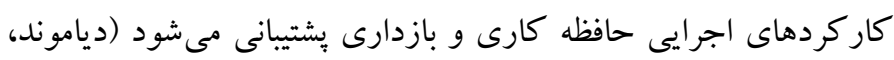

1. Attention Deficit/Hyperactivity Disorder

2. Pieces of Prefrontal

3. Basal Ganglia 
رسد كه فعاليتهاى بلنى مى تواند اهداف اشاره شده را در اين كودكان

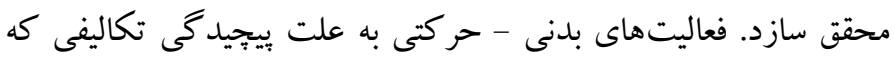

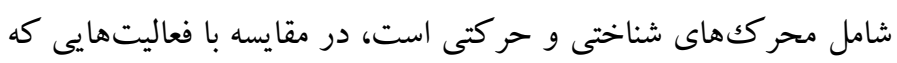

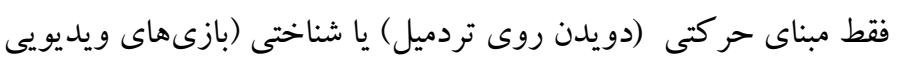

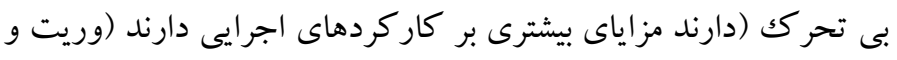

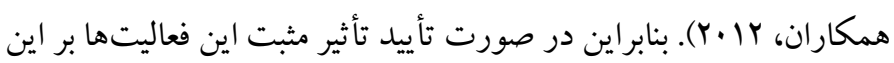
كودكان، مىتوان اميدوار بود كه اين فعاليتها جايكزين بازىهاى ويديويى بى تحر كك يا بازىهاى خشونت آميز و بى هدفى شوند كه مى تواند

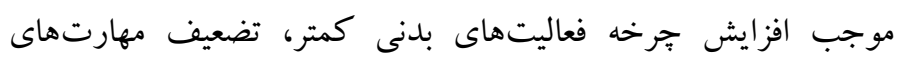
حر كتى و ايجاد برخى مشكلات رفتارى در اين كود كان شود.

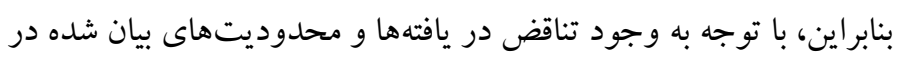

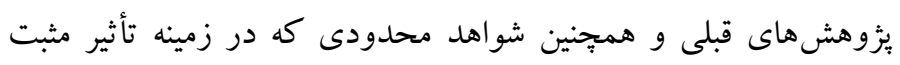

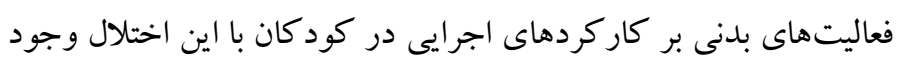

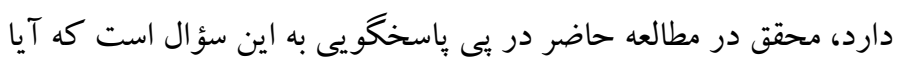

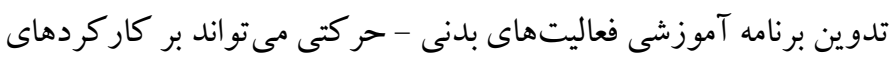

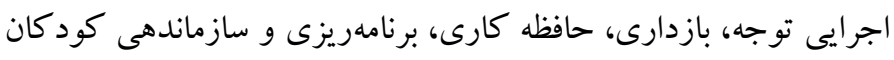

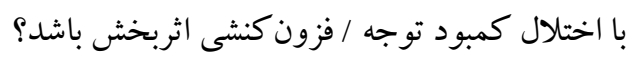

روش الف) طرح هزوهش و شركت كنند كان: روش تحقيق اين بثروهش به

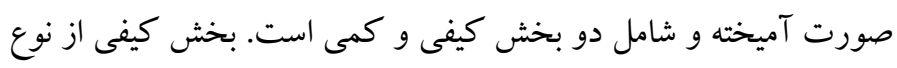
تدوين برنامه آموزشى و بخش كمى شامل روش نيمه آزمايشى از نوع طرح

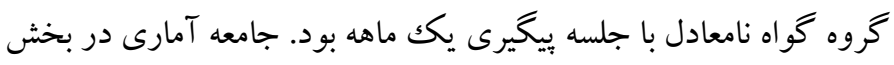

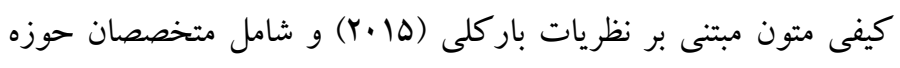

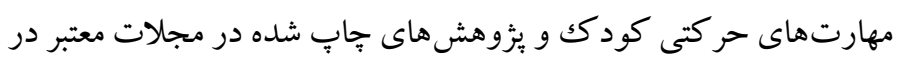

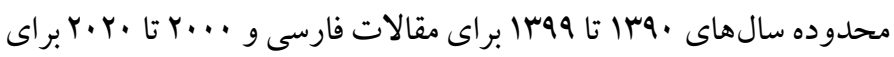
مقالات لاتين در زمينه مداخلههاى حركتى كود كان با اختلال كمبود توجه | فزون كنشى بود. نمونه كيرى در بخش كيفى بر اساس كليدوازمها و متون

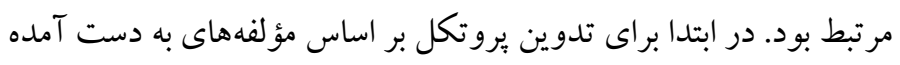

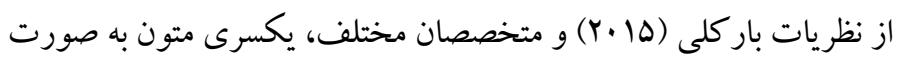
هدفمند انتخاب شدند تا نمونه به اشباع برسد و مطالعه متون تا استخراج

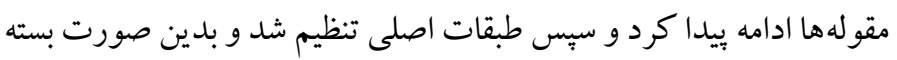

شين، ودون، ويليامز، ديويس و همكاران (ها·r) در مطالعه خود به اين

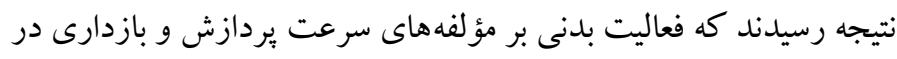

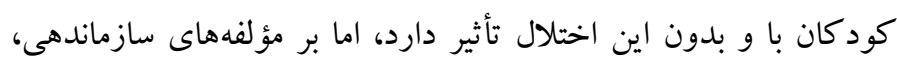

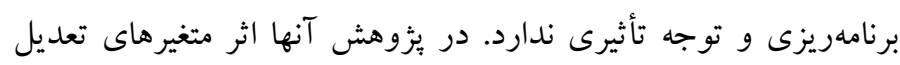

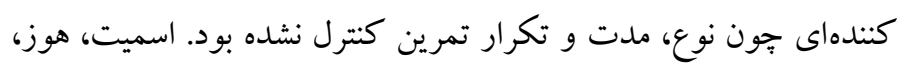

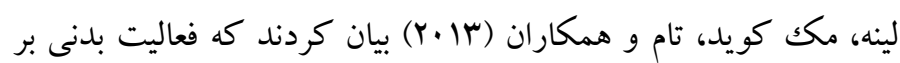

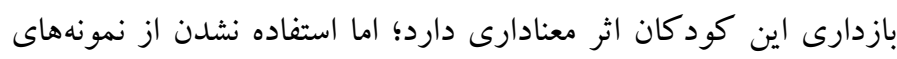

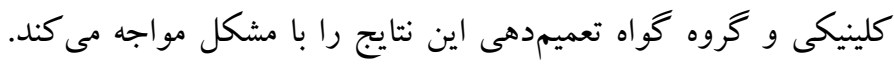

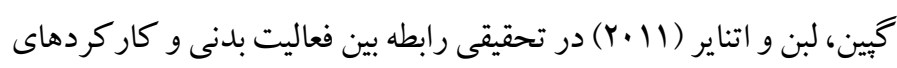

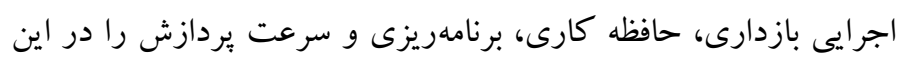

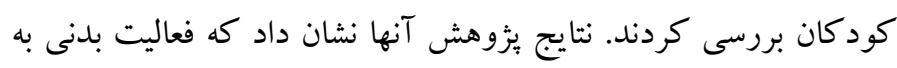

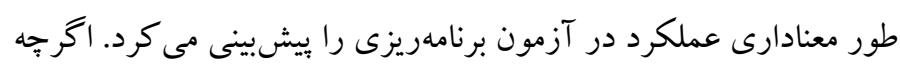

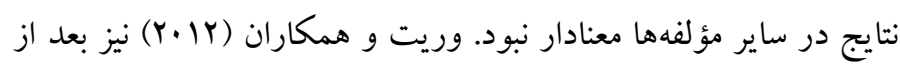

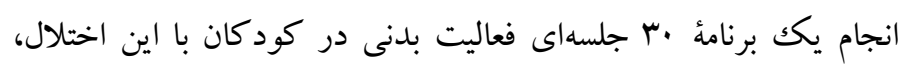

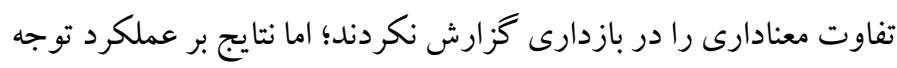

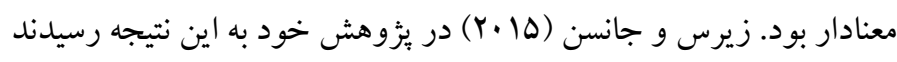
كه فعاليت بدنى بر عملكرد حافظه كارى اين كودكان تأثير دارد، اما دان

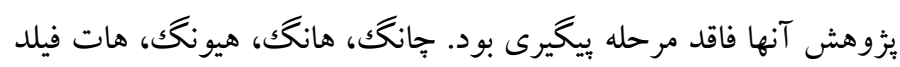

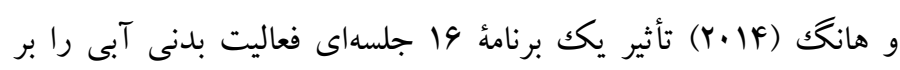

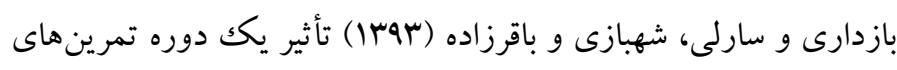

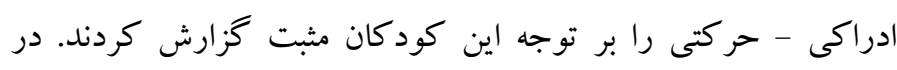
يثزوهشهاى اشاره شده تنها به يكك مؤلفه از كار كردهاى اجر ايى برداخته بردي

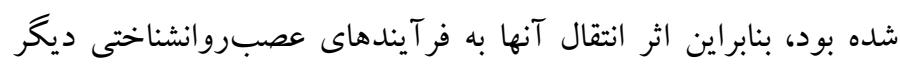

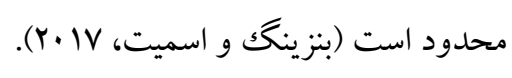

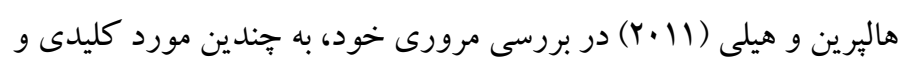

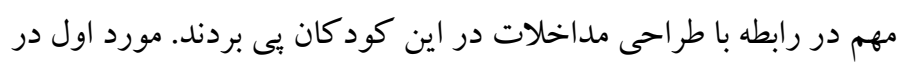

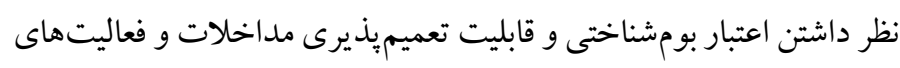

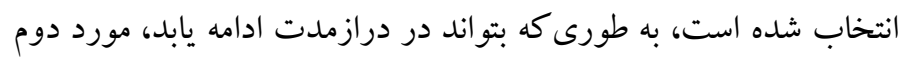

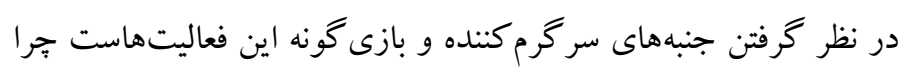
كه وجود شرايط لذتبخش براى اين كود كان به شدت ترغيب كننده

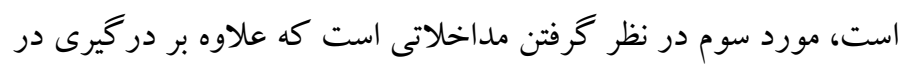

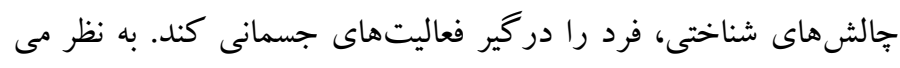


داد منتها در اين زمينه از كارشناس ارشد رشته رفتار حركتى هم كمكك

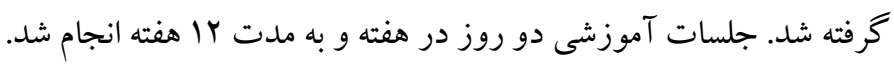

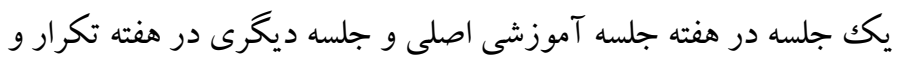

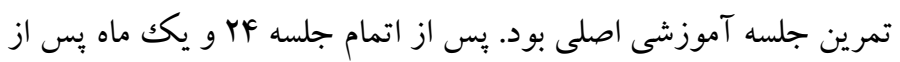

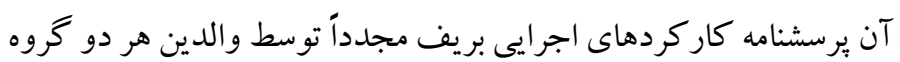
تكميل شد. مطالعه حاضر توسط كميته اخلاق دانشگاه علامه طباطبايى بررسى و با

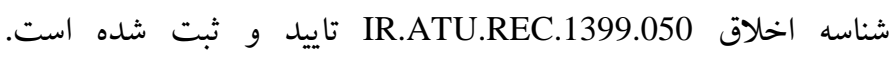

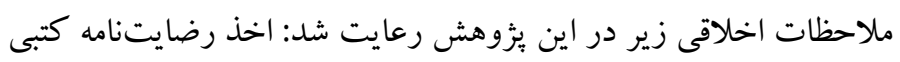

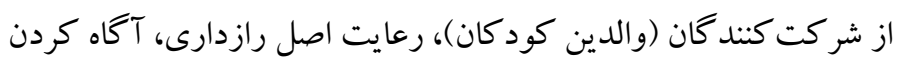

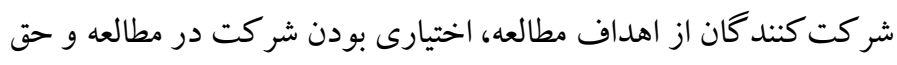
انصراف از مطالعه در هر زمان. دادههاى حاصل از يُوهش با استفاده از روشهاى آمار توصيفى (ميانگين و انحراف معيار) و استباطى (تحليل

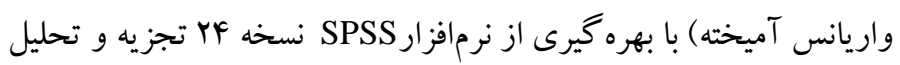

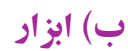
يرسشنامه تشخيصى اختلال كمبود توجه / فزون كنشى: اين برسشنامه بر اساس اطلاعات ارائه شده در وينجمين مجموعه بازنخرى شدهُ تشخيصى و

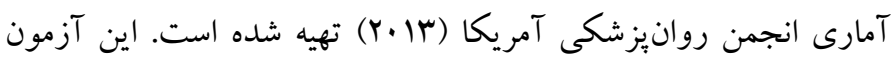

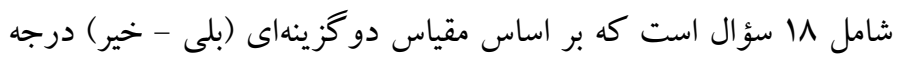

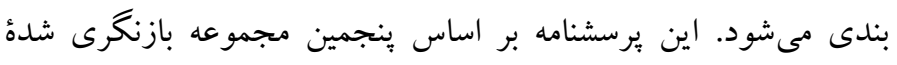

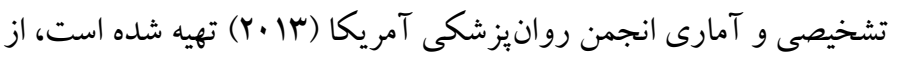

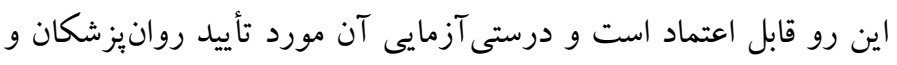

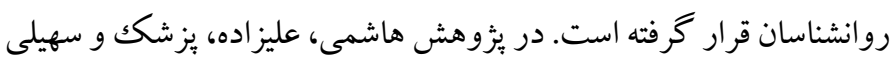

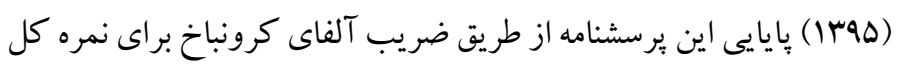

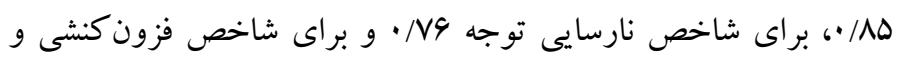

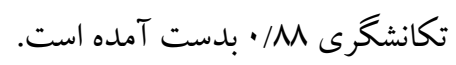

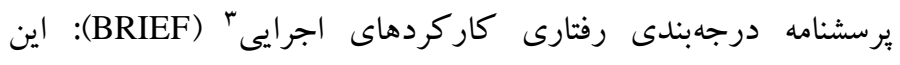

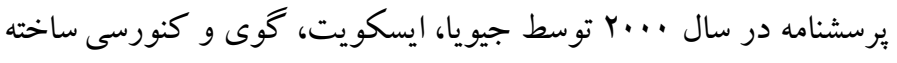

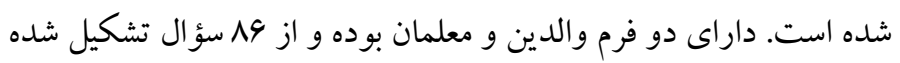

${ }^{3}$. Behavior Rating Inventory of Executive Function
آموزشى تدوين شد. هشت نفر از اساتيد و متخصصان در رابطه با نسبت

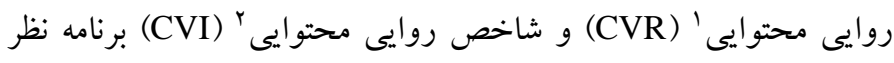
دادند. جامعه بززوهش در قسمت كمى شامل كليه كود كان بسر با باختئلال

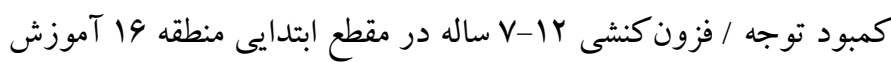

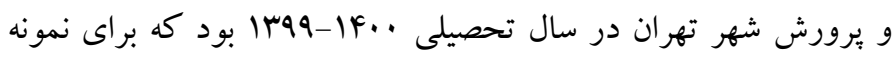

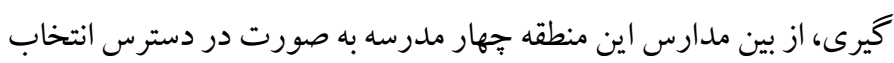

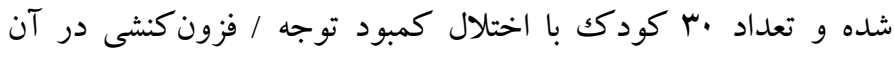

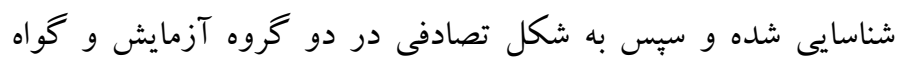

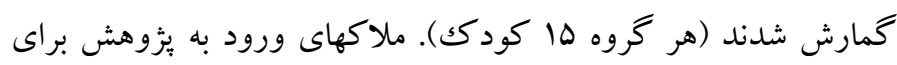

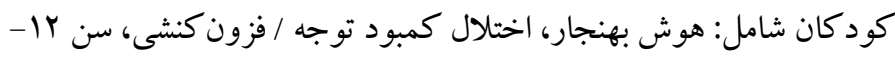
V Vال، جنسيت مذكر، داوطلب بودن و رضايت والدين كودكى، نداشتن

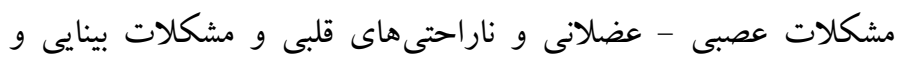

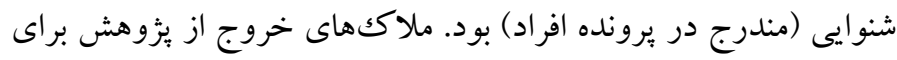

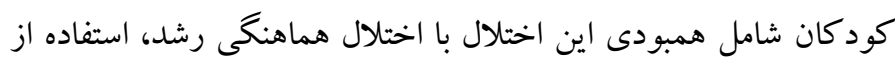

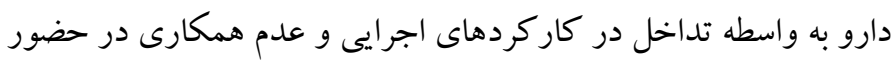

$$
\text { منظم در جلسات آموزشى بود. }
$$

ابتدا از دانشگاه علامه طباطبائى معرفىنامه مبنى بر انجام يزوهش برد براى

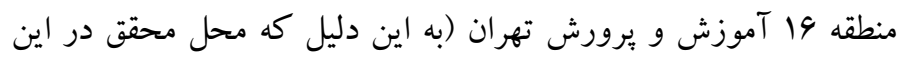

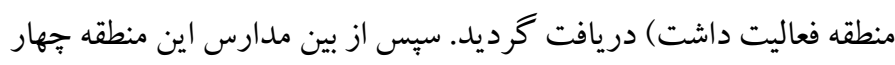

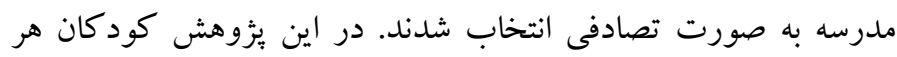

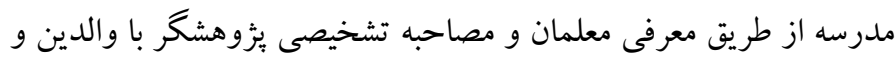

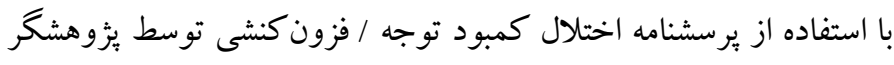

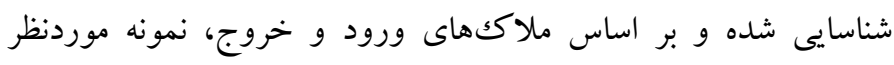

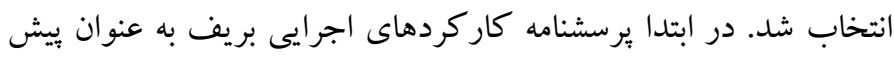

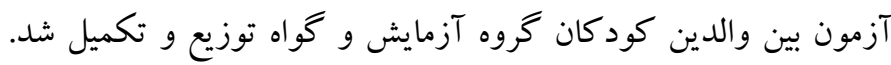

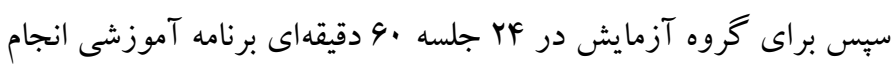

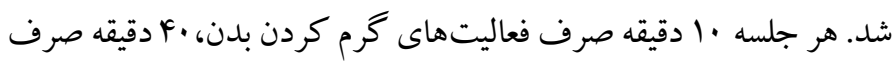

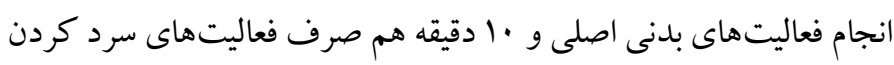

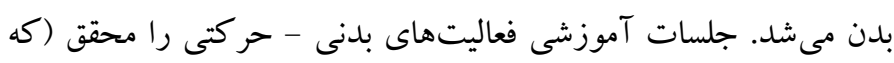

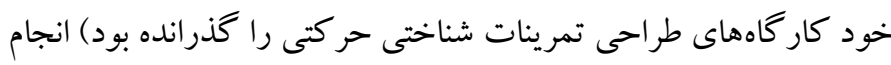

1. Content Validity Raito

2. Content Validity Index 
بازدارى، جا به جايى، كنترل هيجان، آغاز گرى، حافظه كارى، برنامهريزى،

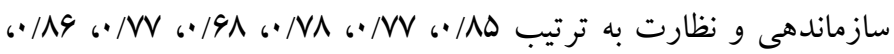

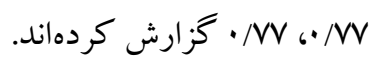

برنامه آموزشى فعاليتهاى بدنى - حر كتى از متون نظريه هاى مربوط به حركت و شناخت و متخصصان مختلف اقتباس شده است. در جدول 1 خلاصه جلسات برنامه آموزشى فعاليتهاى بدنى - حركتى آورده شده

است.
است و با استفاده از مقياس ليكرت سه درجهاى "هيج وقت" و "كاهى اوقات" و "هميشه" به ترتيب از ا تا س توسط والدين يا معلمان كامل مى شود. اين برسشنامه، كاركردهاى اجرايى كود كان سنين ه تا ل1 الهاله را مىسنجد. يرسشنامه حاضر متشكل از دو شاخص تنظيم رفتار (بازدارى، توجه، كنترل هيجان) و شاخص شناختى (آغاز گرى، حافظه كارى، برنامه ريزى راهبردى، سازماندهى و نظارت) است. عبدالمحمدى، عليزاده، غديرى، طيب لى و فتحى (وهr|) در بثزوهشى قابليت اعتماد فرم والدين اين يرسشنامه را با استفاده از ضريب آلفاى كرونباخ براى خردهمقياس هاى

جدول ا. جارجوب جلسات برنامه آموزشى فعاليتهاى بدنى - حر كتى كود كان با اختلال كمبود توجه / فزون كنشى

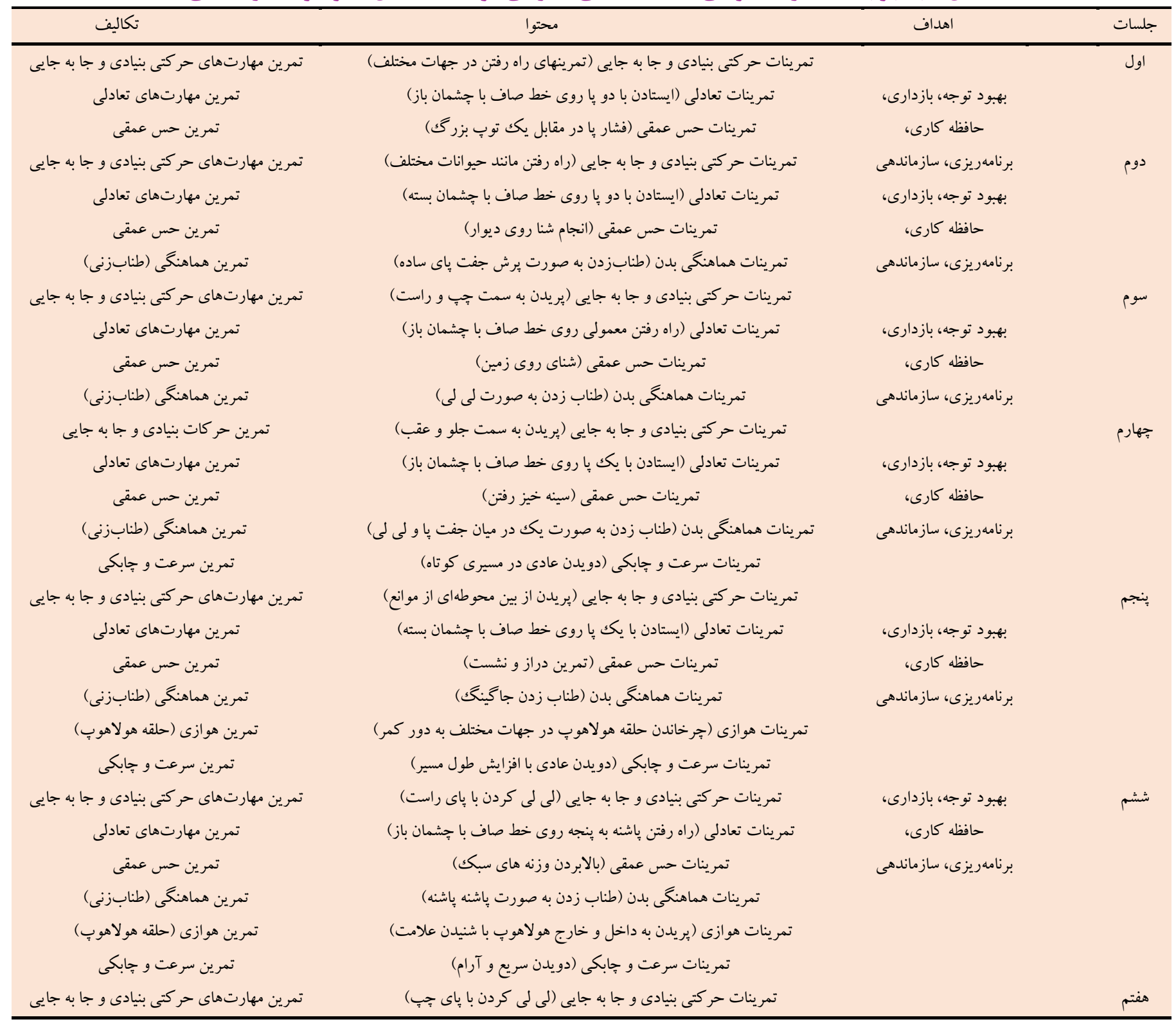




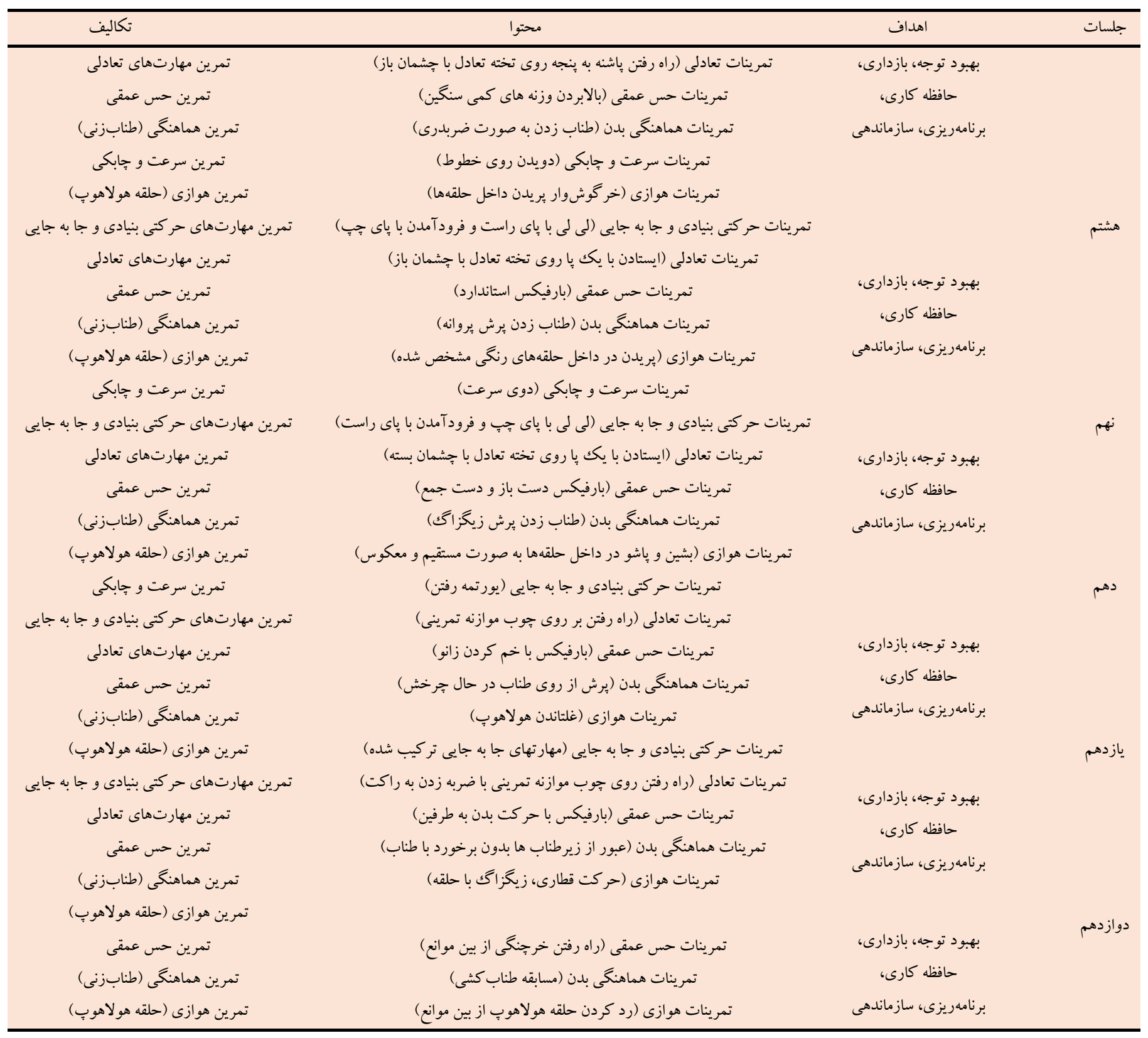

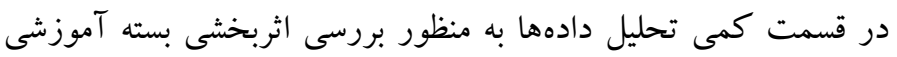

يافته ها

فعاليتهاى بدنى - حركتى بر كاركردهاى اجرايى كود كان با اختلال

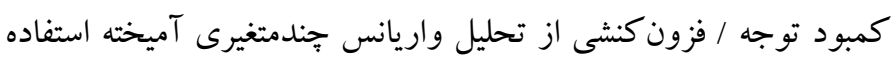
شد. در ابتدا يش فرض هاى مهم اين آزمون آمارى، شامل توزيع نرمال در

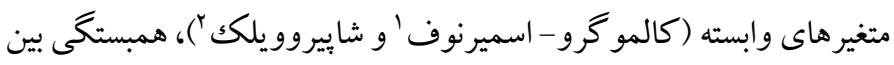

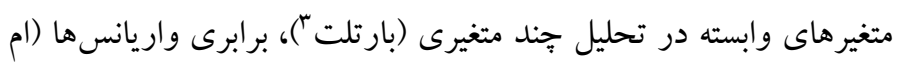

\section{Bartlett's Test}

در بخش كيفى بُزوهش، به منظور تجزيه و تحليل دادههاى حاصل از

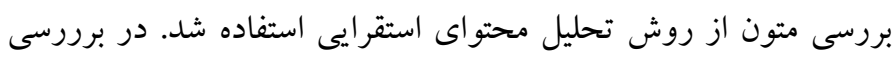

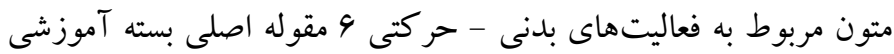

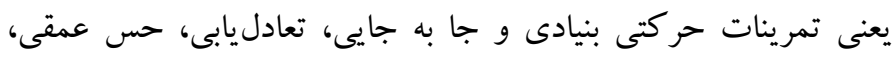

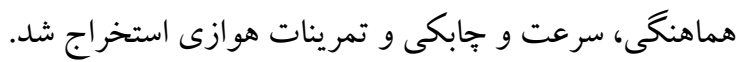

1. Kolmogrof-Smirnof

2. Shapiro-Wilk 
(F= I/9V برقرار است. همجنين، آزمون لوين براى بررسى همكنى واريانس ها معنى دار نبود (ه • • P>) و نشان داد كه همكنى واريانس ها نيز برقرار است. در نهايت آزمون موجلى نشان داد مفروضه كرويت براى همه متغيرهاى

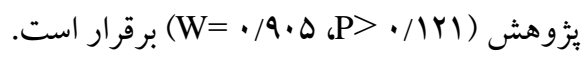

باكس ') و مفروضه كرويت دادهها (مو جلى 'r) بررسى شد. نتايج آزمونهاى كالمو گروف - اسميرنوف و شاييرويلك نشان داد كه دادههاى يثروهش نرمال است. نتايج آزمون بارتلت نشان داد كه ماتريس همبستكى متغيرها

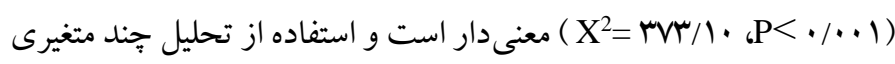

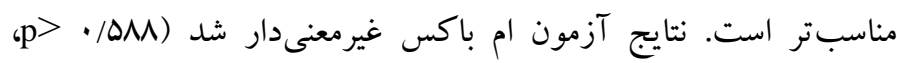

\begin{tabular}{|c|c|c|c|c|c|}
\hline \multicolumn{2}{|c|}{ كروه كواه } & \multicolumn{2}{|c|}{ گروه آزمايش } & \multirow{2}{*}{ مرحله } & \multirow{2}{*}{ متغير } \\
\hline انحر اف معيار & ميانكين & انحر اف معيار & ميانكين & & \\
\hline$r / \cdot r l$ & $1 N / F 9 V$ & r/rAY & M/arr & يِيش آزمون & \\
\hline r/WF & IN/DTr & $r / Y / Q$ & $11 / .9 \mathrm{~V}$ & يֶ آزمون & بازدارى \\
\hline r/AYS & $\mid N / F 9 V$ & Y/IFD & $\mid r / r .$. & ييخيرى & \\
\hline $1 / 1 \ldots$ & $11 / .9 \mathrm{~V}$ & r/DHY & II/ASV & بيش آزمون & \\
\hline $1 / 9 \wedge \Delta$ & $11 / 1 \pi r$ & I/OHF & V/rGV & يس آزمون & توجه \\
\hline l/GFY & 11/ه & $r / I Y$. & V/amr & ييخيرى & \\
\hline $1 / V 90$ & $1 Y / 9 \ldots$ & $r / F 19$ & $\mid r / F 9 V$ & يِش آزمون & \\
\hline l/ars & $\mid r / r .$. & $1 / Y \wedge$. & $1 . / r g V$ & پِ آزمون & حافظه كارى \\
\hline $1 / 94$. & $1 Y / 9 .$. & $1 / 091$ & $1 \cdot / \Lambda \cdot$. & يِيخيرى & \\
\hline$r / .94$ & $1 \cdot / \Delta r$ & $r / \cdot V \cdot$ & $1 \% /$. & بيش آزمون & \\
\hline$r / \cdot \Delta r$ & $1 \cdot / \cdot v$ & Y/YVF & $9 / \wedge$. & بس آزمون & سازماندهى \\
\hline$r / \cdot I V$ & $1 \cdot \% v$ & Y/YAY & $9 / V r$ & ييخيرى & \\
\hline$r / Y q 1$ & $19 / 4$ & $r / .19$ & $19 / 9$ & يِيش آزمون & \\
\hline$r / l \ldots$ & $19 / 1$ & Y/VVF & $19 / 0$ & يس آزمون & برنامهريزى \\
\hline r/FAG & $1 N / \Delta$ & $\Gamma / \mu \cdot \Delta$ & $11 / 9$ & بيخيرى & \\
\hline
\end{tabular}

جدول ". نتايج تحليل واريانس جندمتغيرى اثربخشى بسته آموزشى فعاليتهاى بدنى - حر كتى بر كاركردهاى اجرايى كودكان

\begin{tabular}{|c|c|c|c|c|c|c|c|}
\hline حجم اثر & معنىدارى & درجه آزادى r & درجه آزادى 1 & F & لامبدا ويلكر & \multicolumn{2}{|c|}{ منبع تغيير } \\
\hline - /Ars &.$/ \cdot 1$ & rV & r & $91 / \% 91$ &.$/ 190$ & مرحله & \\
\hline$\cdot / 1 \cdot 1$ &.$/ \cdots 1$ & TV & r & $\Delta G / V M F$ & . /l9Y & مرحله گتروه & درون گروهى \\
\hline -/V99 &.$/ \cdot 1$ & rI & $\wedge$ & $1 \cdot / F F Y$ & $\cdot / r \cdot 1$ & مرحله متشغير & \\
\hline.$/ 419$ &.$/ \cdot 1$ & YA & 1 & IT/IFY & - & كروه & بين گروهى \\
\hline
\end{tabular}

كروهى نيز بيانكر اين است كه حداقل بين يكى از متغيرهاى ينج كانه در

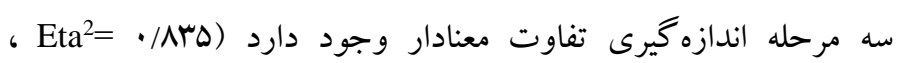
.$(\mathrm{F}=9 \wedge / \mathrm{4} 96 \mathrm{P}<\cdot \cdots)$

نتايج جدول f نشان ميدهد اثر معنىدار براى عامل گروه، مرحله و تعامل مر حله با كروه در مؤلفه بازدارى (F=و)

2. Mauchly's Test
در بررسى اين فرضيه مقادير لامبداى ويلكز براى نتيجه گيرى در جدول ارائه شده است. نتايج نشان مىدهد اثر معنىدار براى عامل كروه وجود دارد (19/\%/ • حداقل بين يكى از ينج مؤلفه كاركردهاى اجرايى كروه گواه و آزمايش تفاوت معنادار وجود دارد. همجنين آزمونهاى جندمتغيرى اثرات درون 


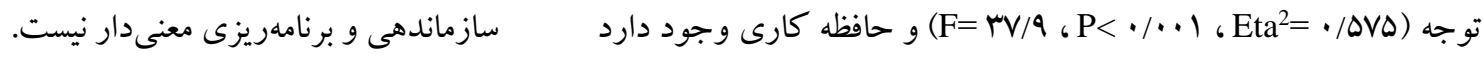

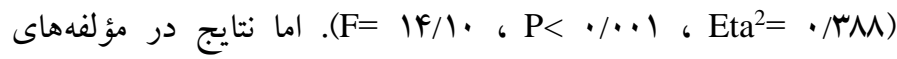

جدول ع. نتايج تحليل واريانس تكمتغيرى آميخته اثربخشى بسته آموزشى فعاليتهاى بدنى - حر كتى بر كار كردهاى اجرايى كودكان

\begin{tabular}{|c|c|c|c|c|c|c|c|c|}
\hline حجم اثر & معنىدارى & $\mathrm{F}$ & ميانگين مجذورات & درجه آزادى & مجموعه مجذورات & \multicolumn{2}{|c|}{ منبع تغيير } & متغير \\
\hline - MFF &.$/ \cdot 1$ & $\Lambda I / \Delta V F$ & $\mid r F / I F$ & r & YGN/Yq & مرحله & & \\
\hline - N $F q$ &.$/ \cdot 1$ & $\wedge r / r q q$ & $I T V / I F$ & r & $r V F / Y q$ & مر حله گرووه & & بازدارى \\
\hline$\cdot / F M$ &.$/ .1$ & $r Q / V \cdot r$ & $F F \cdot / \cdot 1$ & 1 & $F F \cdot / \cdot 1$ & كروه & بين گروهى & \\
\hline . /DYG &.$/ \cdot 1$ & $M Y \cdot r V$ & $F Y / I T$ & r & $\Lambda F / T V$ & مرحله & & \\
\hline$\cdot / \Delta V \Delta$ & $\cdot / \cdot 1$ & rV/arr & $01 / 01$ & r & $1 \cdot r / . r$ & مر حله & & توجه \\
\hline - &.$/ \cdot 1$ & $1 D / Y \Delta F$ & $111 / 11$ & 1 & $111 / 11$ & كروه & بين گروهى & \\
\hline$\cdot / \backslash \wedge \vee$ & $\cdot / \mu r$ & G/FrT & $9 / 91$ & r & $1 \% / r 4$ & مرحله & & \\
\hline - & $\% / \cdot 1$ & $|f / \mu|$. & $\mid F / A$ & r & YQ/VG & مر حله & & حافظه كارى \\
\hline$\cdot / r \cdot 4$ &.$/ \cdot 14$ & $F / r \Delta V$ & $\Delta Q / Y I$ & 1 & $\Delta Q / Y I$ & كروه & بين گروهى & \\
\hline$\cdot 1 \cdot \mathrm{Vq}$ &.$/ .91$ & $r / F I V$ & $1 / r r$ & r & $r / F V$ & مرحله & & \\
\hline.$/ \cdot 1$ & $\cdot / V \Delta \Delta$ & • TAN & $\cdot / l f$ & r & $\cdot / 79$ & مر حله گ گروه & & سازماندهى \\
\hline.$/ 199$ & $.191 \mathrm{~V}$ & $\cdot / r \Delta \Delta$ & $r / r)$ & 1 & $r / r)$ & كروه & بين گروهى & \\
\hline.$/ 194$ & . r r & $9 / 94 A$ & $\Delta / \mu F$ & r & $1 \cdot 199$ & مرحله & & \\
\hline .1 .04 & . /ArG & $\cdot / \Lambda \wedge$. & $\cdot / l F$ & r & $\cdot / 79$ & مرحله گروه & & برنامهريزى \\
\hline$\cdot / \cdots \Delta$ & $\cdot / V \cdot 9$ & $\cdot / \mathrm{Fr}$ & Y/AF & 1 & Y/AF & كروه & بين گروهى & \\
\hline
\end{tabular}

جدوله. نتايج آزمون تعقيبى بن فرونى مقايسه ميانتينهاى كار كردهاى اجرايى كود كان

\begin{tabular}{|c|c|c|c|c|c|c|}
\hline معنى دارى & خطا & تفاوت & & & كروه & متغير \\
\hline$\cdot / \cdot$ & $\cdot / v$ & $* \mathrm{~V} / \wedge 9 \mathrm{~V}$ & מֶس آزمون & يِيش آزمون & & \multirow{6}{*}{ بازدارى } \\
\hline$\%$ & $\cdot / \Delta F$ & *a/NTr & ييخيرى & ييش آزمون & آزمايش & \\
\hline.$/ \cdot r$ & $\cdot / 4$. & $*_{1 / 1 r-}$ & ييخيرى & پِ آزمون & \multirow{4}{*}{ كواه } & \\
\hline $1 / \cdots$ & $\cdot / r r$ & $\cdot / \cdot V-$ & يس آزمون & بيش آزمون & & \\
\hline $1 / \cdots$ & מז/. & $\cdot / \cdot$ & ييخيرى & يِش آزمون & & \\
\hline $1 / \cdots$ & $\cdot / 4$. & $\cdot / \cdot v$ & بيخيرى & ֶِ آزمون & & \\
\hline$\cdot / \cdot$ & $\cdot / 4 A$ & $* F / 9$ & ي" آزمون & ييش آزمون & \multirow{3}{*}{ آزمايش } & \multirow{6}{*}{ توجه } \\
\hline$\cdot / \cdot$ &.$/ 9$ & $* r / q \mu$ & ييخيرى & بيش آزمون & & \\
\hline.$/ 4 q$ & $\cdot / \& \Delta$ & $.19 \mathrm{VV}-$ & ييخيرى & پِ آزمون & & \\
\hline $1 / \cdots$ & $\cdot / r$. & $\cdot / \cdot \mathrm{V}-$ & پِ آزمون & بيش آزمون & \multirow{3}{*}{ كواه } & \\
\hline$\cdot / r \cdot \Delta$ & $\cdot / r F$ & $\cdot / q V-$ & ييخيرى & يِش آزمون & & \\
\hline ./99. & $\cdot / 4 q$ & $\cdot / 4 \cdot-$ & ييخيرى & ֶِ آزمون & & \\
\hline$\cdot / \cdot$ & $\cdot / 4 q$ & $*_{Y / Y}$. & پِ آزمون & يِش آزمون & \multirow{3}{*}{ آزمايش } & \multirow{6}{*}{ حافظه كارى } \\
\hline$\cdot / \cdot$ & $\cdot / F r$ & $*_{1} / 9 \mathrm{~V}$ & بيخيرى & ييش آزمون & & \\
\hline$\cdot / 44$ & D & - & يِيَيرى & پِ آزمون & & \\
\hline$\cdot / \ldots$ & $\cdot / T \Delta$ & $\cdot / 9 \cdot-$ & يس آزمون & يِش آزمون & \multirow{3}{*}{ كواه } & \\
\hline $1 / \cdots$ & $\cdot / \mu F$ & $\cdot /$. & ييخيرى & ييش آزمون & & \\
\hline$\cdot / \pi 4$. & . & $\cdot 19$ & ييخيرى & يس آزمون & & \\
\hline $1 / \cdot \cdot$ & $\cdot / r$. & $\cdot / r$ & گِ آزمون & ييش آزمون & آزمايش & برنامهريزى \\
\hline
\end{tabular}




\begin{tabular}{|c|c|c|c|c|c|c|}
\hline \multirow{2}{*}{ معنى دارى } & \multirow{2}{*}{$\frac{\text { خطا }}{\cdot / / 1}$} & \multirow{2}{*}{ تفاوت } & \multicolumn{2}{|c|}{ مرحله } & \multirow[t]{2}{*}{ كروه } & \multirow[t]{2}{*}{ متغير } \\
\hline & & & بيخيرى & بيش آزمون & & \\
\hline $1 / \cdot \cdot$ & $\cdot / T \Delta$ & $.1 .9 \mathrm{~V}$ & ييخيرى & بֶ آزمون & & \\
\hline$\cdot / \cdot \wedge \mathrm{V}$ & $\cdot / 19$ & $\cdot / F V$ & بِ آزمون & ييش آزمون & & \\
\hline - rar & $\cdot / 79$ & $\cdot / A V$ & ييخيرى & ييش آزمون & كواه & \\
\hline $1 / \cdots$ & $\cdot / \pi \Lambda$ & $\cdot / \cdot$ & بيخيرى & بֶ آزمون & & \\
\hline $1 / \cdot$ & $\cdot / T V$ & .1 .94 & پِ آزمون & يِش آزمون & & \\
\hline$\cdot / 11$ & $\cdot / 49$ & $\cdot / 99 \mathrm{~V}$ & يبيَيرى & بيش آزمون & آزمايش & \\
\hline & $\cdot / T V$ & $\cdot 19 .$. & ييخيرى & پِ آزمون & & \\
\hline $1 / \cdots$ & $\cdot / T \Lambda$ & $\cdot / r V$ & يس آزمون & ييش آزمون & & s \\
\hline$\cdot / \cdot \wedge V$ & $\cdot / \mu \Lambda$ & . $/ 94$ & بيخيرى & يِش آزمون & كواه & \\
\hline . $/ q T V$ & . & $.19 \mathrm{~V}$ & ييخيرى & يس آزمون & & \\
\hline
\end{tabular}

سازماندهى تأثيرى نداشته است. در ادامه به تبيين اثركذارى و يا عدم

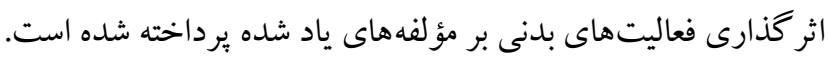
نتايج يزوهش نشان داد كه فعاليتهاى بدنى - حركتى بر مؤلفه توجه

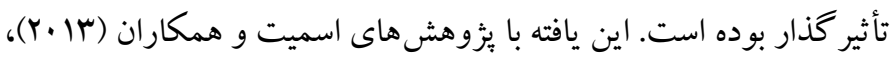

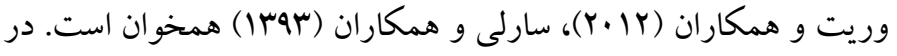

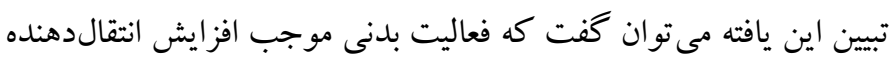

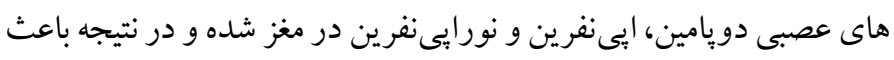

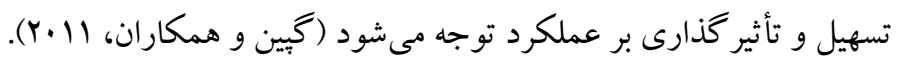

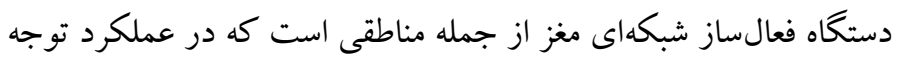
نقش به سزايى دارد. اين دستكاه در قسمت بايين مغز قرار داشته و مغز را

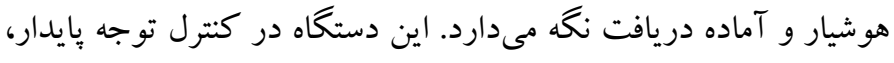
بازدارى و بخشبندى رفتار نقش مهمى دارد. مطالعات عقدههاى و قاعدهاى دردي نشان مى دهند كه فعاليت هاى بدنى مى تواند سبب بهبو د عملكر د اين دستكاه

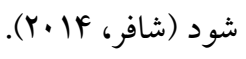

برنامه آموزشى فعاليتهاى بدنى - حركتى منجر به بهبود بازدارى در

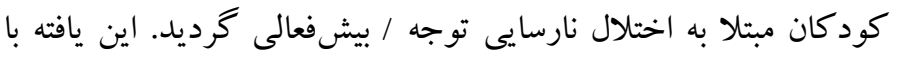

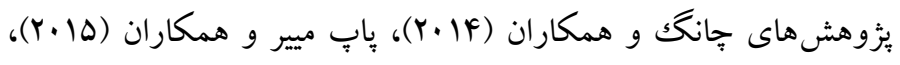

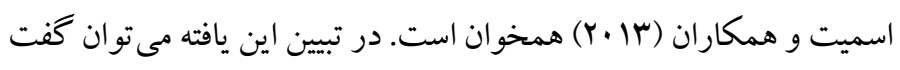
كه فعاليت بدنى برخى از انتقالدهندههاى عصبى خاص مانند دويامين را كه در كنترل برانگيختخى و بازدارى دخيل است، در اين كود كان تنظيم

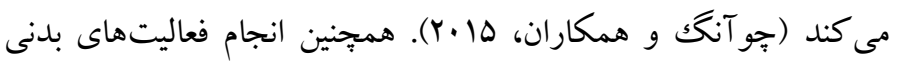

نتايج مقايسه زوجى حاصل از آزمون تعقيبى بنفرونى نشان مىدهد كه در

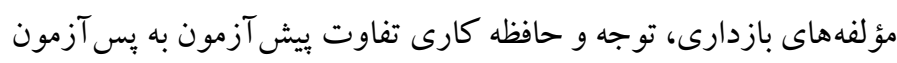

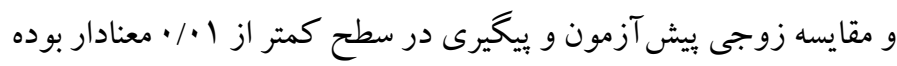

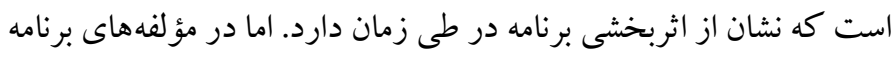
ريزى و سازماندهى اثربخشى آموزش معنادار نبود

بحث و نتيجه تيرى

در قسمت كيفى بزوهش، نسبت روايى محتوايى برنامه در دامنه •A/ • تا ا

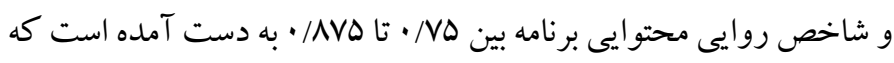

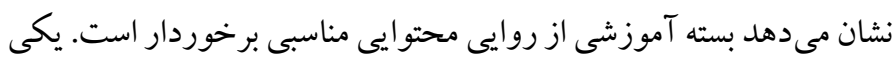

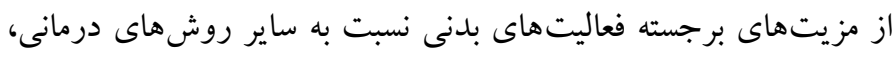

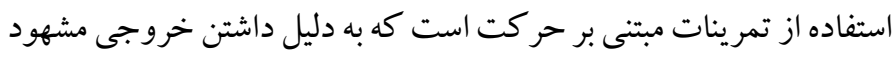
و قابل سنجش و همجنين بهره جستن از فعاليتهاى حر كتى كه خود از

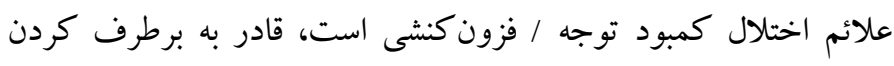

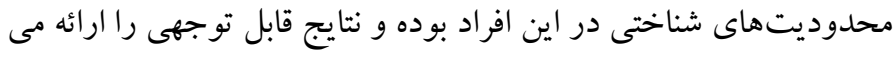
دهد. به عنوان مثال تمرينات مربوط به حر كات بنيادى و جا به جايى (مانند دويدن، يريدن، خرجنگ راه راه رفتن و...) به صورت ساختارى با بهبود

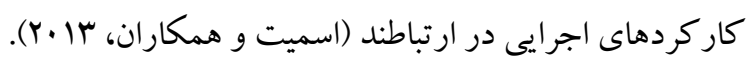
در قسمت كمى، نتايج يزوهش نشان داد كه برنامه آموزشى فعاليتهاى إنيان بدنى - حر كتى منجر به بهبود كار كردهاى اجر ايى در كود كان با اختلال كمبود توجه / فزونكنشى در مؤلفه هاى توجه، بازدارى و حافظه كارى

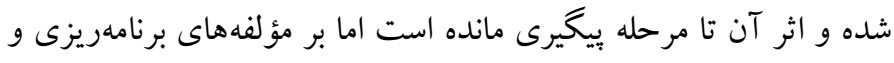


بثزوهش حاضر مانند هر مطالعه ديخرى داراى محدويتهايى مانند عدم

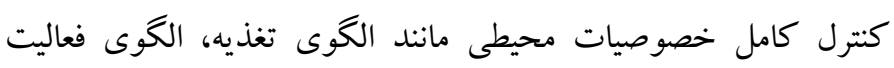
روزمره و استراحت، تنوع و تفاوت در وضعيت اجتماعى، اقتصادى،

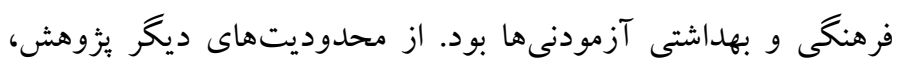

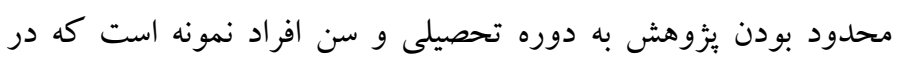

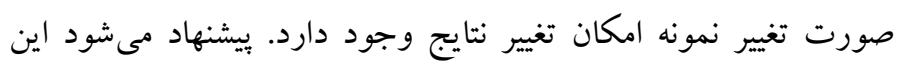

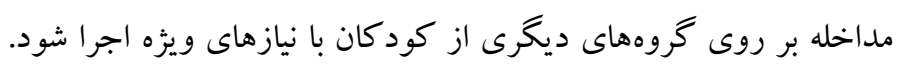

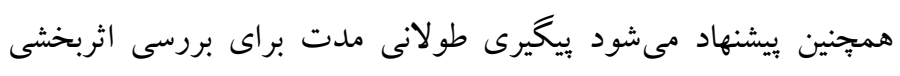

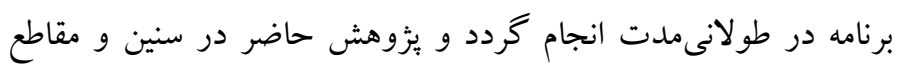
تحصيلى مختلف و همجنين بر مؤلفه هاى ديخر كار كردهاى اجرايى انجام

ملاحضات اخلاقى بيروى از اصول اخلاق ثئوهش: اين مقاله بركرفته از رساله دكترى نويسنده اول در

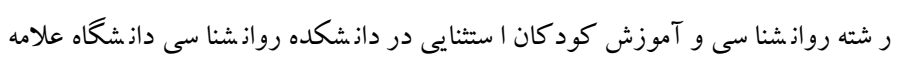

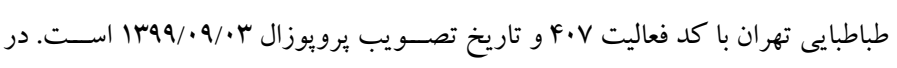

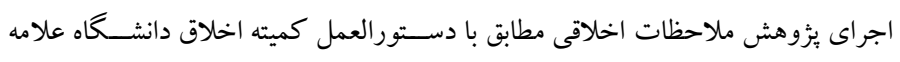

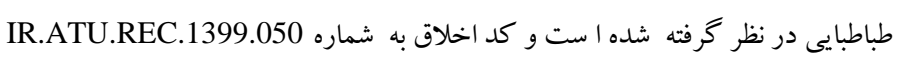

دريافت شده است.

حامى مالى: اين يُروهش در قالب رساله دكترى و بدون حمايت مالى مى باشد.

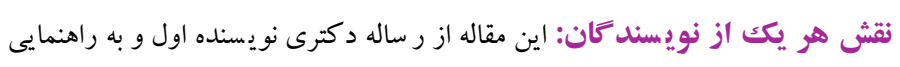

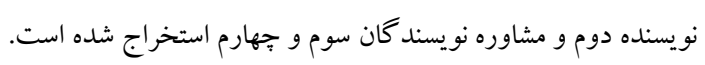

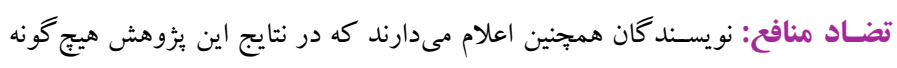
تضاد منافعى وجود ندارد.

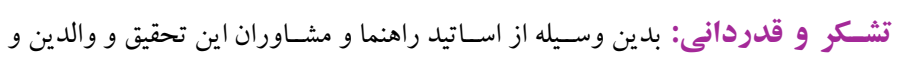

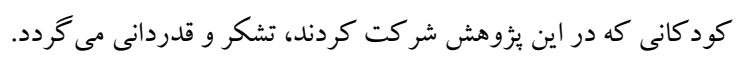

موجب افزايش سطح دويامين و عملكرد بهتر عقدههاى قاعدهاى در مغز

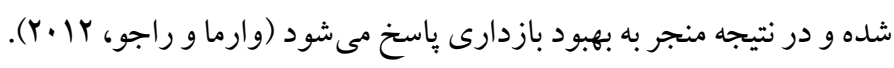

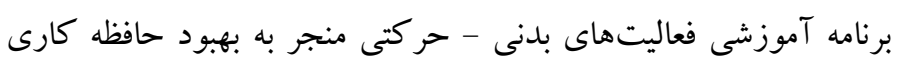

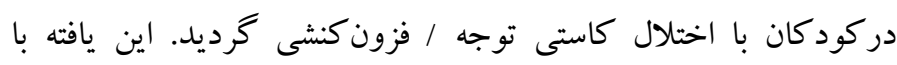

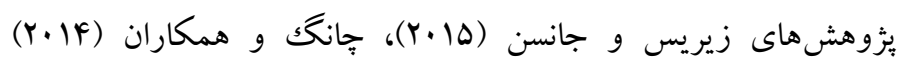
همخوان است. در تبيين اين يافته مى توان كفت كه فعاليت بدنى با تنظيم

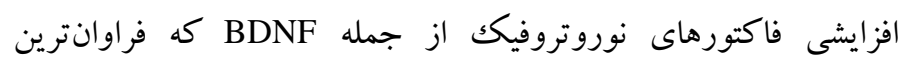

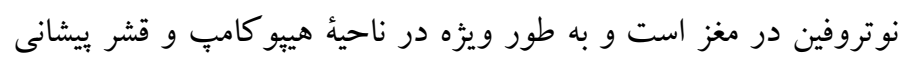

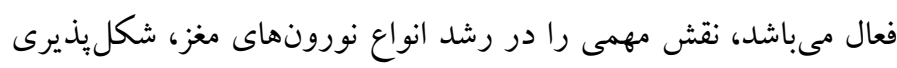

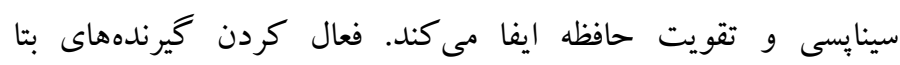

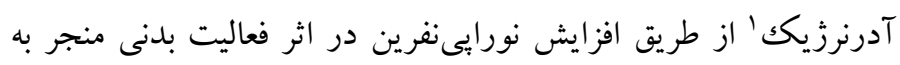
افزايش ميزان بيان زن فاكتور رشد دهنده عصبى مشتق از مغز (BDNF) و

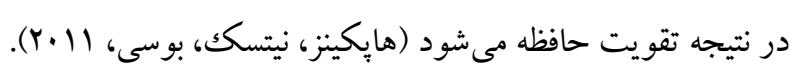

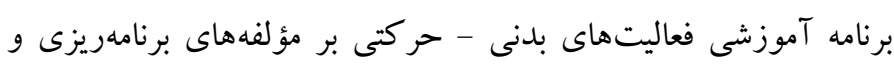

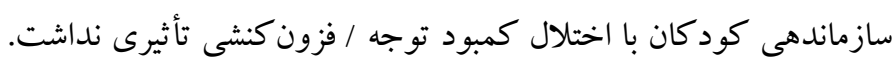

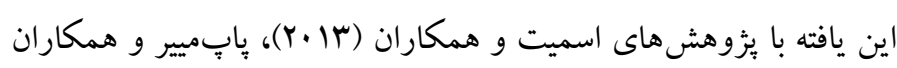

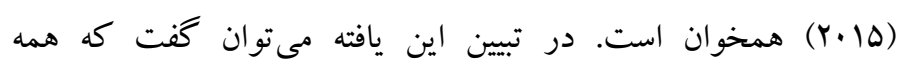
كاركردهاى اجرايى به يكك اندازه به تأثير فعاليت بدنى حساس نيست افتئن

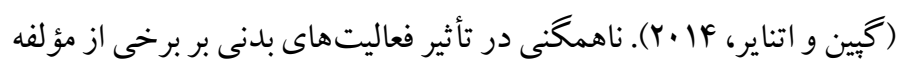

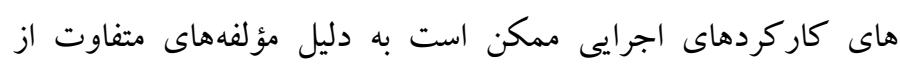
كار كردهاى اجرايى باشد كه مسيرهاى رشدى مترديى متفاوتى دارند. فر آيندهاى

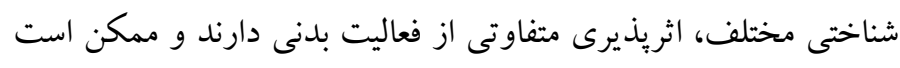

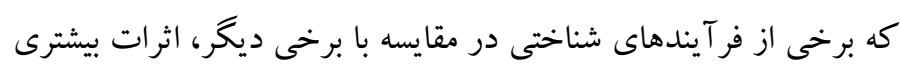
از فعاليت بدنى دريافت كنند (بست، · · (Y).

${ }^{1}$. Beta drenergic receptors 


\section{References}

Abdul Mohammadi K, Alizadeh H, Ghadiri Surmanabadi F, Tayebli M, Fathi A. (2017). Evaluation of psychometric properties of Behavioral Rating Questionnaire of Executive Functions (BRIEF) in children 6 to 12 years old. Journal of Educational Measurements, 30, 103-125. (Persian) 10.22054/JEM.2018.24457.1596. [Link]

Alizade H. (2005). Theoretical explanation attention deficit / hyperactivity: The pattern of behavioral inhibition and self-control nature. Journal Except Child, 5(3). 323-348. (Persian). [Link]

American psychiatric association (2013). Diagnostic and statiscal manual of mental disorder: DSM-5. 5 th ed. Arlington, VA, American Psychiatric Association Washington, DC. https://doi.org/10.1176/appi.books.978089042559. [Link]

Amouzadeh F, Honarmand P, Rahim zadeh M, Ghariyagh Zandi H, Rostami R. (2020). The impact of fifa on the ADHD symptoms in students with ADHD. Journal of Psychological Science, 19(93), 10491058. (Persian). [Link]

Barkley, R. A. (2015). Attention-deficit hyperactivity disorder: A handbook for diagnosis and treatment. New York, NY: Guilford Publications. [Link]

Barkley, R. A. (2004). Adolescents with attention-deficit deficit/ hyperactivity disorder: an overview of empirically based treatments. Journal of psychiatric practice, 10, 39-56. DOI: 10.1097/00131746200401000-00005. [Link]

Barkley, R. A. (2006). The relevance of the still lectures to attention-deficit/ hyperactivity disorder: a commentary. Journal of Attention Disorders, 10(2), 137- 40. DOI: 10.1177/1087054706288111. [Link]

Benzing, V., \& Schmidt, M. (2017). Cognitively and physically demanding exergaming to improve executive functions of children with attention deficit hyperactivity disorder: a randomised clinical trial. BMC pediatrics, 17(1), 8. doi: 10.1186/s12887-016-0757-9. [Link]

Best, J. R. (2010). Effects of physical activity on children's executive function: Contributions of experimental research on aerobic exercise. Journal of Developmental Review, 30, 331-351. DOI: 10.1016/j.dr.2010.08.001. [Link]

Chang, Y. K., Hung, C. L., Huang, C. J., Hatfield, B. D., \& Hung, T. M. (2014). Effects of an aquatic exercise program on inhibitory control in children with ADHD: A preliminary study. Archives of
Clinical Neuropsychology, 29(3), 217- 223. doi: 10.1093/arclin/acu003. [Link]

Chuang, L. Y., Tsai, Y. J., Chang, Y. K., Huang, C. J., \& Hung, T. M. (2015). Effects of acute aerobic exercise on response preparation in a Go/No Go Task in children with ADHD: An ERP study. Journal of Sport and Health Science, 4(1), 82-88. DOI:10.1016/j.jshs.2014.11.002. [Link]

Diamond, A. (2013). Executive functions. Annual review of psychology, 64,135-168. doi.org/10.1146/annurev-psych-113011-143750. [Link]

Gapin, J., Etnier, J. (2014). Parental Perceptions of the effects of exercise on behavior in children and adolescent with ADHD. Journal of Sport and Health Science, 3, 320-325. doi.org/10.1016/j.jshs.2013.03.002. [Link]

Gapin, J. I., Labban, J. D., \& Etnier, J. L. (2011). The effects of physical activity on attention deficit hyperactivity disorder symptoms: The evidence. Preventive Medicine, 52, 70-74. doi: 10.1016/j.ypmed.2011.01.022. [Link]

Gioia, G. A., Isquith, P. K., Guy, S. C., \& Kenworthy, L. (2000). Behavior Rating Inventory of Executive Function. Child Neuropsychology, 6, 235-238. doi.org/10.1076/chin.6.3.235.3152 .[link].

Halperin, J. M., \& Healey, D. M. (2011). The influences of environmental enrichment, cognitive enhancement, and physical exercise on brain development: can we alter the developmental trajectory of ADHD? Neuroscience \& Biobehavioral Reviews, 35(3), 621-634. doi: 10.1016/j.neubiorev.2010.07.006. [Link]

Hashemi Malekshah S, Alizadeh H, Pezeshk S, Soheili F. (2016). The effectiveness of parenting education with Adler approach on executive functions of children with attention deficit/ hyperactivity disorder. Cognitive Science News Quarterly, 18 (4), 88-99. (Persian). [Link]

Hopkins, M. E., Nitecki, R., Bucci, D. J. (2011). Physical exercise during adolescence versus adulthood: differential effects on object recognition memory and brain derived neurotrophic factor levels. Neuroscience, 194, 84-94. DOI: 10.1016/j.neuroscience.2011.07.071. [Link]

Locascio, G., Mahone, E. M., Eason, S. H., \& Cutting, L. E. (2010). Executive dysfunction among children with reading comprehension deficits. Journal of Learning Disabilities, 43, 441-454. Doi: 10.1177/0022219409355476. [Link] 
Marcus, S. C., Wan, G. J., Kemner, J. E., Olfson, M. (2005). Continuity of methylphenidate treatment for attention deficit/hyperactivity disorder. Archives of Pediatric and Adolescent Medicine, 159, 572-578. doi:10.5539/jedp.v3n2p65. [Link]

Mikami, A. Y., \& Hinshaw, S. P. (2006). Resilient adolescent djustment among girls: buffers of childhood peer rejection and attention deficit/hyperactivity disorder. Journal of Abnormal Child Psychology, 34, 825-839. doi: 10.1007/s10802-006-9062-7. [Link]

Nejati, V., Najian, A. Akbarpour, F. (2017). The effectiveness of motor based cognitive rehabilitation on improvement of working memory of children with ADHD. Journal of Psychological Science, 15(60), 504-517. [Link]

Neudecker, C. H., Meves, N., Reimers, A. K., Woll, A. (2015). Exercise Interventions in Children and Adolescents with ADHD: A Systematic Review. Journal of Attention Disorders, 23(4), 1-19. Doi: 10.4103/0366-6999.200541. [Link]

Piepmeier, A.T., Shih, C.-H., Whedon, M., Williams, L., Davis, M., Henning, D., Park, S., Calkins, S.D., \& Etnier, J. L. Journal of Sport and Health Science, 4, 97-104. doi:10.1016/j.jshs.2014.11.004. [Link]

Polanczyk, G. V., Salum, G. A., Sugaya, L. S., Caye, A., \& Rohde, L. A. (2015). Annual research review: A meta-analysis of the worldwide prevalence of mental disorders in children and adolescents. Journal of Child Psychology and Psychiatry, 56, 345-365. Doi: 10.1111/jcpp.12381. [Link]

Sarli A., Shahbazi M., Bagherzadeh F. (2014). Investigate effectiveness of perceptual- motor tasks on visual and auditory attention of children with Attention Deficit Hyperactivity Disorder. Motor Behavior, 15, 47-60. (Persian). [Link]

Schmith, A. L., Hoza, B., Linnea, K., Mcquade, J. D., Tomb, M., Vaughn, A. J., Shoulberg, E. K. \& Hook, H. (2013). Pilot physical activity intervention reduces severity of ADHD symptoms in young children. Journal of Attention Disorders, 17, 70-82. DOI: 10.1177/1087054711417395. [Link]

Schaefer, R. S. (2014). Auditory rhythmic cueing in movement rehabilitation: findings and possible mechanisms. Philosophical Transactions of the Royal Society Biological, 369(1658), 1-9. https://doi.org/10.1098/rstb.2013.0402. [Link]

Varma, C., \& Raju, P. (2012). Yoga Therapy in Pediatrics. Education in Medicine Journal, 3(6), 1-4. Doi: 10.9754/journal.wmc.2012.003506. [Link]
Verret, G. M., Berthiaume, C., Gardiner, P., Beliveau, L. (2012). A physical activity program improves behavior and cognitive functions in children with ADHD: An exploratory study. Journal of Attention Disorders, 16(1), 71-80. DOI: 10.1177/1087054710379735. [Link]

Ziereis, S., \& Jansen, p. (2015). Effects of physical activity on executive function and motor performance in children with ADHD. Research in Developmental Disabilities, 38,181-191. DOI: 10.1016/j.ridd.2014.12.005. [Link] 